\title{
Multimedia -assisted reading in Spanish and its relationship with the cognitive control of field dependence and field independence
}

Laura Janes Little

West Virginia University

Follow this and additional works at: https://researchrepository.wvu.edu/etd

\section{Recommended Citation}

Little, Laura Janes, "Multimedia -assisted reading in Spanish and its relationship with the cognitive control of field dependence and field independence" (2001). Graduate Theses, Dissertations, and Problem Reports. 2346.

https://researchrepository.wvu.edu/etd/2346

This Dissertation is protected by copyright and/or related rights. It has been brought to you by the The Research Repository @ WVU with permission from the rights-holder(s). You are free to use this Dissertation in any way that is permitted by the copyright and related rights legislation that applies to your use. For other uses you must obtain permission from the rights-holder(s) directly, unless additional rights are indicated by a Creative Commons license in the record and/ or on the work itself. This Dissertation has been accepted for inclusion in WVU Graduate Theses, Dissertations, and Problem Reports collection by an authorized administrator of The Research Repository @ WVU.

For more information, please contact researchrepository@mail.wvu.edu. 


\author{
Multimedia-Assisted Reading \\ In Spanish \\ And Its Relationship With The Cognitive Control \\ Of Field Dependence And Field Independence
}

Laura Janes Little, B.A., M.A.

Dissertation submitted to the

College of Human Resources and Education

at West Virginia University

in partial fulfillment of the requirements

for the degree of

Doctor of Education

in

Curriculum and Instruction

C. Kenneth Murray, Ed.D., Chair

W. Michael Reed, Ed.D.

Frank W. Medley, Ph.D.

Perry Phillips, Ed.D.

W. Scott Bower, Ph.D.

Department of Educational Theory and Practice

Morgantown, West Virginia

2001

Keywords: Multimedia, Spanish, reading, cognitive controls, recall protocol 


\begin{abstract}
Multimedia-Assisted Reading In Spanish And Its Relationship With The Cognitive Control

Of Field Dependence And Field Independence
\end{abstract}

\title{
Laura J. Little
}

This study examines the influence of the cognitive controls of field independence and field dependence on the use of a multimedia-assisted reading program and reading recall. The participants were 11 university students of intermediate Spanish as a second language. The participants were classified as field dependent or field independent based on GEFT scores. The participants read a passage about Mayan architecture that was converted to a multimedia-assisted format. Participants could access as many or as few of the multimedia aids as they chose. After completing the reading, a recall measure was obtained in which participants wrote everything they could recall of the passage. Independent ttests examined the relationship between cognitive control and the use of multimedia aids, and the relationship between cognitive control and recall score. None of these differences were significant. However, since there were apparent differences in the access patterns, future research should include replication of the study with a larger sample. 


\section{ACKNOWLEDGEMENTS}

This document would not have been possible without the help of many people. I would like to thank my committee for their insights and guidance. They spent several hours with me, providing inspiration and suggestions during this process. Special thanks go to my chair, Dr. C. Kenneth Murray, for meeting with me for hours and guiding and encouraging this research. Special thanks are also due Dr. W. Michael Reed, who continued to support me long after his departure from West Virginia Unviersity.

I would also like to thank several people from the Foreign Languages Department at West Virginia University for their support. Thanks to Dr. Frank Medley for providing guidance in the field of foreign language research, and for putting me in contact with the people in the Foreign Languages Department that helped me to collect the data. A special thanks goes to Tracy Dingess and the staff of the CALL lab for the assistance they provided in preparing the machines and during the data collection. I would also like to thank Dr. Jeffrey Bruner and Cristina Davalos for providing classroom time for data collection and solicitation of participants. And finally, a heartfelt thanks to the participants in this study, without whom this study would not have been possible.

Several people have provided other types of support as well. I would like to thank Dr. Dan Hursh for constructive comments on very early drafts of this document. Joe Ervin helped me to figure out the tracking capabilities of HyperStudio, and for that I am truly grateful. I would also like to thank Roberto 
Ramirez of Honduras.net for his generosity in allowing me to use his pictures as part of the treatment. And a very special thanks to Rodolfo Argueta, my secondary researcher, for volunteering his time to assist with the analysis of the data.

And finally, many people have provided moral support along this difficult path. Dr. Roxann Humbert and Dr. Robert Kefferstan of WVNET were most supportive of my latter efforts in finalizing this study, both in terms of release time and well-timed words of encouragement. Susan Lantz encouraged me all along the way, mainly over excellent dinners she prepared. Thus she fed me spiritually and physically. Dr. Kim DiPino also provided encouragement and support, as well as a constructively critical eye, throughout the entire process. And finally, a special thanks to my parents, Gary and June Little. They listened and cared when things were not progressing as anticipated, and they loved me through it all. To all of these people, thank you from the bottom and the top of my heart. 
Dedicated to the memory of my grandmothers

Cecile Janes Little

Laura Ruth Saunders 
Table of Contents:

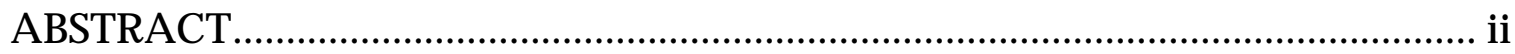

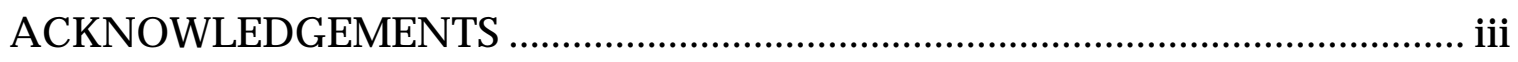

DEDICATION

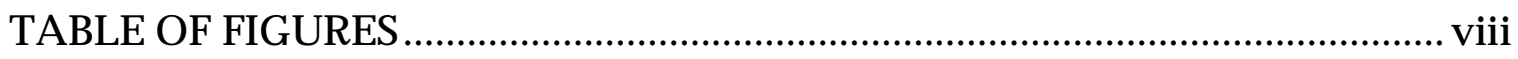

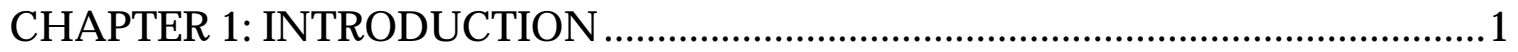

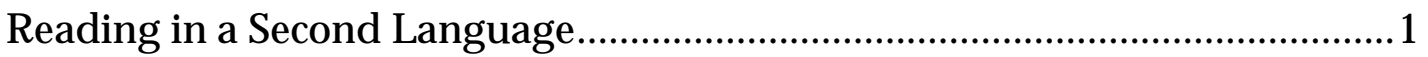

Computers in Second-Language Instruction .....................................................2

Individual Differences in Second-Language Learning .......................................

Use of Multimedia Elements in L2 Learning .....................................................5

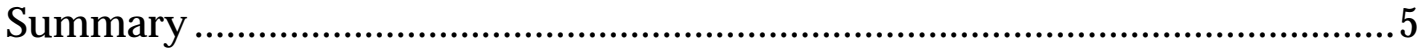

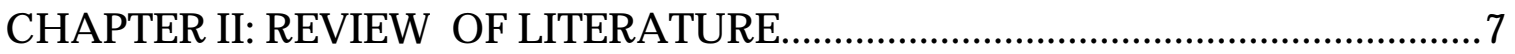

Issues in Reading in a Foreign Language .........................................................

Cultural Factors in Reading Comprehension .................................................

Differences in L1 and L2 Reading ………..................................................10

Background Knowledge and L2 Reading Comprehension.............................12

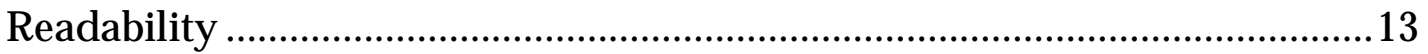

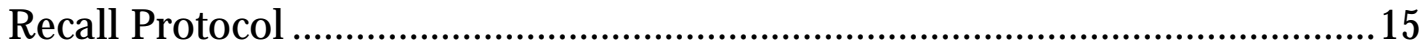

Computers, Schema Theory and L2 Reading ................................................15

Use of Aids in Computer-Assisted Reading .................................................17

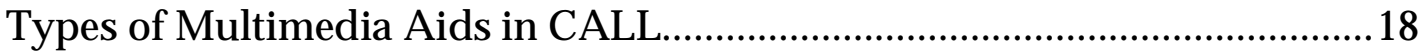

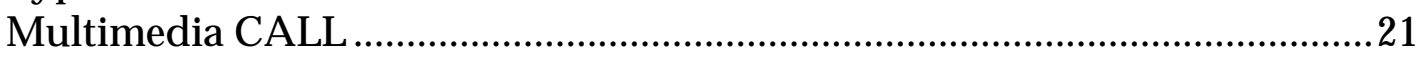

Computer-Assisted Reading ..........................................................................23

Individual Differences and Language Learning..............................................24

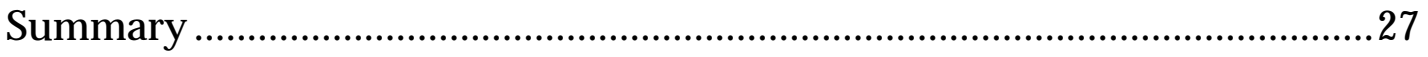

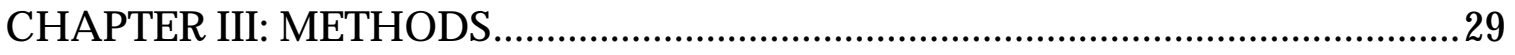

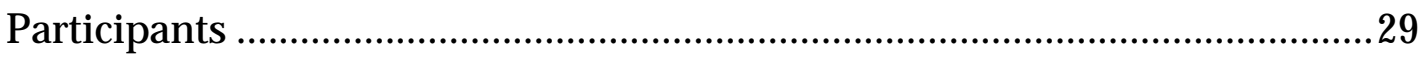

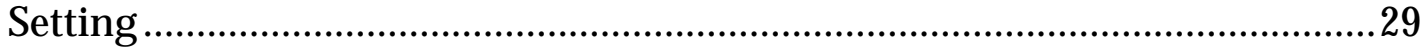

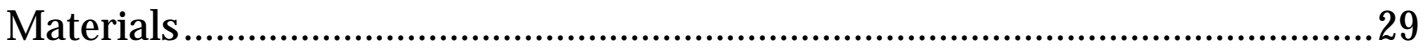

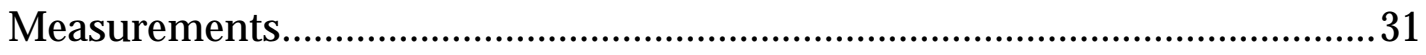

Independent Variable 31

Dependent Variables 32

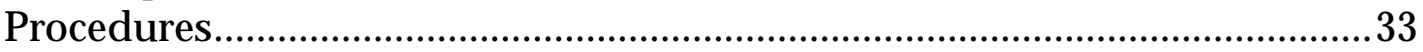

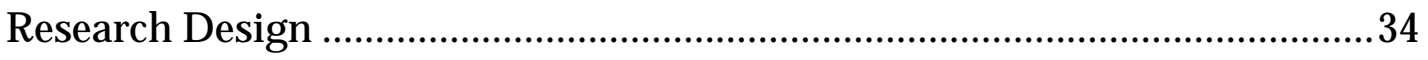


CHAPTER FOUR: ANALYSIS

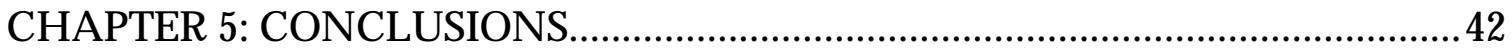

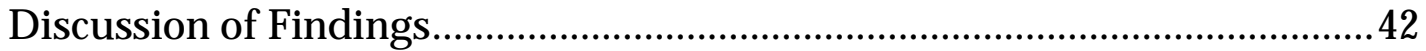

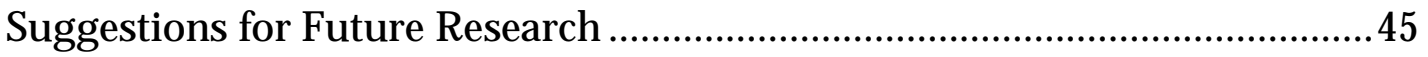

Summary and Conclusions ...........................................................................4

APPENDIX A: TEXT OF READING PROGRAM DIVIDED INTO IDEA UNITS 49

APPENDIX B: DEMOGRAPHIC DATA QUESTIONNAIRE ................................52

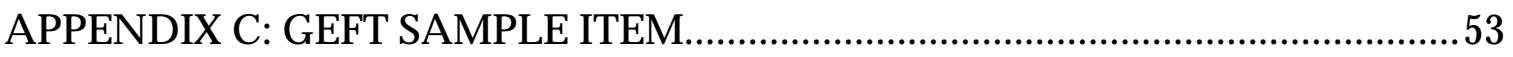

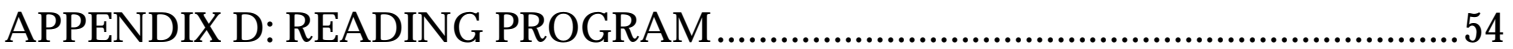

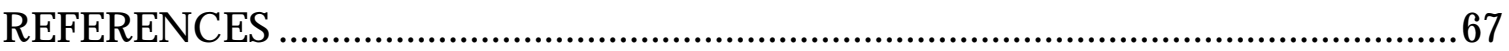




\section{TABLE OF FIGURES}

Table 1: Mean Multimedia Accesses by Cognitive Control.....................................35

Table 2: T-test Results for Vocabulary Accesses ........................................................37

Table 3: T-test Results for Sound Accesses ................................................................38

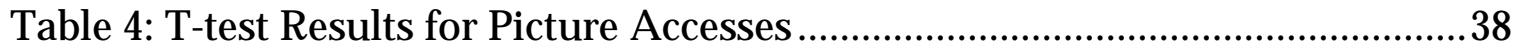

Table 5: T-test Results for Total Multimedia Aid Accesses ..........................................39

Table 6: T-test results for Recall .............................................................................40

Table 7: T-test Results for Recall (excluding outlier) ................................................41 


\section{CHAPTER I: INTRODUCTION}

\section{Reading in a Second Language}

In learning a second language, students face a major set of readjustments. Not only do they have to learn a new set of vocabulary and orthography, they must also learn new connotations of words and phrases, a new structure, and a culture that may be drastically different from their own. Once the students master the above elements, they and their teacher may think that they are then ready to read authentic texts in the target language (L2), only to find that interference from their first language and culture colors the interpretations of the words.

Of course, some languages present more difficulty to L2 learners than others. Spanish tends to be an easier language for native English speakers to master than certain other languages because of several similarities between the two languages. The first obstacle that some L2 learners experience is the difference in orthography. Native English speakers learning Russian, for example, must first learn the Cyrillic alphabet before they can identify the words. Since Spanish uses the same Roman alphabet that English does, learners of Spanish do not have to overcome differences in orthography. Spanish and English also share many cognates, words with similar spellings and meanings, such as mucho/much. 
In a second-language situation, students are much less likely to use strategies that they employ every time they read their native language, such as inferencing. They assume that they must understand each word in order to obtain meaning from the L2 text, even though they may be adept at inferring the meanings of unfamiliar words in their native language (Aspatore, 1984). They also tend to believe that a one-to-one correspondence exists between words in the target language and words in the native language, when this is not the case. Even when all the words are familiar to them, they may not be able to put them together and construct meaning from the text (Bensoussan, 1986). Unfamiliar cultural items, idiomatic expressions, and different structural elements may add to the difficulty of this task (Bensoussan, 1986; Davis, 1992; Steffensen, Joag-Dev \& Anderson ,1979).

\section{Computers in Second-Language Instruction}

Although the computer has long been used in language instruction, its use has been primarily for drill and practice (Warschauer, 1996). Hence, reading programs have focused on vocabulary and word-attack skills which can help in the simple decoding of a text, but do not assist the learner in activating previous schema that may be relevant, or providing background information vital to understanding the text. Although the computer has the capability to do all of these things, reading programs have often been electronic page-turners, little different from existing reading textbooks. Garrett (1991) points out the common assumption that computers can and should be used to teach reading in the same 
ways as textbooks are used, which "perpetuates our least sophisticated approaches to the teaching of reading, and ignores the computer's ability to offer learners ways of learning that go far beyond simple decoding" (Garrett, p. 5). Individual Differences in Second-Language Learning Learners of a second language are not homogeneous. Even when the L2 learners share the same native language and native culture, they do not always learn a second language equally well. Individual differences between learners may account for some of the variation in facility in L2 learning. Research has shown that the construct of field dependence and field independence (FD/FI) can account for some of the differences in second language learning (Carter, 1988; Chapelle \& Green, 1992; Chapelle \& Jamieson, 1986; Chapelle \& Roberts, 1986; Hansen \& Stansfield, 1982). Field independent students tend to seek out information that they find relevant or interesting, while field dependent students accept the existing determination of information. Field independent students excel at restructuring information, while field dependent students excel at seeing a particular situation as a coherent whole. Field dependent and field independent learners benefit from different instructional strategies, which can be difficult to accommodate in the same classroom. On the whole, field independent students consistently outperform field dependent students in language learning tasks (Brown, 1977; Carter, 1988; Chapelle \& Green, 1992; Chapelle \& Jamieson, 1986; Chapelle \& Roberts, 1986; Hansen \& Stansfield, 1982). However, it is possible that the measures of language proficiency themselves favor FI learners. 
In studies investigating the relationship between the cognitive control of FD/FI and language learning, language proficiency has been measured by grammatical tests and by cloze exercises (Carter; Chapelle \& Roberts; Chapelle \& Green). These types of exercises favor those who excel at analytical learning, such as FI students. However, it is possible that FD students may excel when language proficiency is measured by other methods. Since grammatical tests and cloze exercises reflect an analytic knowledge and understanding of the language, these would favor the more analytic FI learners. (Chapelle \& Green) Other types of assessment may well capitalize on areas in which FD students excel. FD students may be better able to understand the global and cultural context of a reading passage than are FI students. However, the type of assessment often associated with reading comprehension is that of questions following a passage selecting specific pieces of information. This method of assessment requires readers to focus on discrete elements of the passage, rather than the passage as a whole. FI students, given their analytic orientation, would tend to excel at this type of task. FD students, given their global orientation, would be hypothesized to understand the context of the passage while being less able to isolate discrete elements. Thus, testing the reading comprehension via a free recall protocol rather than a cued method would give FD students a chance to articulate the global context of the passage, which is as important as remembering isolated individual facts about the passage. 
Use of Multimedia Elements in L2 Learning

The inclusion of multimedia elements can help to provide the context that all L2 learners need in order to accurately interpret a text. Audio files can help learners become aware of intonation and vocal connotations that can help textual comprehension, pictures can illustrate concepts that are difficult to explain verbally, and video clips can provide students with a window into the culture about which they are reading. Textual information can also be helpful in providing an explanation of background knowledge necessary for the processing of information, as well as provide strategies for students to use in interpreting the texts. All these elements are not likely to be useful for all learners, but the incorporation of these elements can help students of various learning styles to learn the target language so that all learners become competent in that language.

\section{Summary}

The purpose of this investigation is to examine the reading habits of field dependent and field independent second-language learners, more specifically, the preferred multimedia annotations of each type. Multimedia-supported reading texts can help L2 learners to understand the text (Chun \& Plass, 1996a; Chun \& Plass, 1996b). However, the question of exactly which multimedia aids most support L2 learning has not been addressed in depth. Those studies which have been conducted (Aweiss, 1994-5) have focused on the different types of multimedia aids, not on the individual differences in L2 learners. Liu (1995) and Liu and Reed (1995) have determined that there is a difference in the types of 
multimedia aids accessed by L2 vocabulary learners. However, to date no research has examined whether these same patterns hold true for reading comprehension, which is a much different task than vocabulary acquisition, since reading comprehension necessitates the knowledge of how the passage relates to and reflects the cultural context of the reading and of the structure of the writing, as well as the decoding of vocabulary words.

The second issue is whether there is a difference in the amount of information that the learners having different cognitive controls recall from the reading passage. The research questions guiding this study are 1) What is the effect of cognitive control (FD/FI) on use of multimedia annotations? and 2) What is the effect of cognitive control (FD/FI) on reading comprehension? 


\section{CHAPTER II: REVIEW OF LITERATURE}

Issues in Reading in a Foreign Language

Reading in a foreign language (L2) is a daunting proposition for many learners of Spanish as a second language. The first problem that they face is the problem of unfamiliar vocabulary. This lack of vocabulary knowledge can lead to two undesirable outcomes: either students will misunderstand the major ideas of the reading passage, or they keep looking up unfamiliar words rather than inferring their meaning. (Liou, 1997). With experience and practice, L2 learners become more discriminating in their lookup behavior. Hulstijn (1993) noted that experienced L2 learners refine their lookup strategies and do not look up the meanings of all unfamiliar words. Instead, they try to infer the meanings of these words. If they cannot infer the meaning of the unfamiliar word to their satisfaction, they look up the meanings of words they consider relevant, but not those they find irrelevant (Hulstijn). Hulstijn's sample consisted of L2 learners that were in their fourth or fifth year of language study, so it can be supposed that these learners were sophisticated readers experienced in negotiating meaning in a second language. Hulstijn concludes that "words which were deemed relevant in terms of reaching the goal of reading were looked up more frequently than words deemed irrelevant" (Hulstijn, p. 145). These advanced students knew how to use the reading tools to most efficiently reach the goal of understanding the passage, and were not distracted by unknown irrelevant 
words. This is a far cry from Aspatore's (1984) relatively inexperienced readers, who exclaim, "How can I tell you what it's about if I don't know all the words?" (Aspatore, p. 297)

\section{Cultural Factors in Reading Comprehension}

But even when the learners are familiar with all the words, there are still obstacles to their reading comprehension. Even in the native language (L1), students unfamiliar with the cultural context of a passage can have difficulties understanding the intentions of the characters and even the action itself. One interesting study (Reynolds et al., 1982) examined the reactions of black and white American students to a reading about a cultural practice that is much more common within the African-American community. The black readers were much more likely to correctly interpret the reading passage as "sounding," a form of ritual insult common in the African-American community, while white students interpreted the reading passage as a physical fight. The white students lacked appropriate cultural schemata to interpret the reading correctly. This lack of relevant cultural schemata caused the black students to be amazed that the white students misinterpreted the reading. "What's the matter?" one black student said. "Can't they read?" (Reynolds et al., p. 365).

These cultural differences are magnified when two distinct cultures are considered, rather than two subcultures of a mainstream culture. In a landmark study, Steffensen, Joag-Dev, and Anderson (1979) examined the differences in meaning ascribed to texts about weddings. Indian and US participants read two 
readings: one about an Indian wedding and one about a US wedding. US participants read the US passage more quickly than the Indians. The US subjects recalled more details from the text, and they recalled these details more accurately. They were also able to make appropriate inferences judging the text reflecting their native culture. As expected, the reverse was true for the Indians: they read the Indian text more quickly and more accurately than the Americans. Occasions of an interpretation completely opposite of the information given in the text were also documented. For example, the US text indicated that the bride wore the same wedding dress as her grandmother. The Americans correctly interpreted this section as indicating a value for tradition, while the Indians misinterpreted this section as indicating that the bride was out-of-date: "She was looking alright except the dress was too old and out of fashion" (Steffensen, JoagDev \& Anderson, p.21). The appropriate cultural implication (American) was complimentary, while the other (Indian) was derogatory. Americans also misinterpreted passages. The American implication of the text "We are all hoping that she does not have too hard a time adjusting to her new life" was recalled by Americans as "Well, I hope Prema enjoys her new life" (Steffensen, Joag-Dev, \& Anderson, p. 25). This is much more optimistic than the correct Indian interpretation: "I hope she will not have a hard time adjusting to her new family," (Steffensen, Joag-Dev, \& Anderson, p. 25), as well as negating the influences of the extended family on the new wife. The subjects in this study were all native speakers of English, or had native proficiency in English, so familiarity with the 
language was not an issue in this instance. When language proficiency is not at the native or near-native level, the lack of proficiency causes problems in addition to the problems of cultural misunderstandings. When language learners are engaged in a reading task, they must deal with issues of a foreign culture as well as linguistic issues such as vocabulary, grammatical structure, and idiomatic expressions. Thus, the reading task for $\mathrm{L} 2$ learners that are not yet proficient is much more difficult than in the preceding study, for the L2 learners are struggling with new vocabulary and structures, as well as an unfamiliar culture.

\section{Differences in L1 and L2 Reading}

Many language learners incorrectly assume that reading in a foreign language is tantamount to mere translation. Hence, they are likely to do a wordfor-word translation into their native language, without regard for sentence structure, idiomatic expressions, or cultural differences (Aspatore, 1984; Bensoussan, 1986). Such a translation will be awkward at best, and incorrect at worst (Aspatore). Bensoussan documents EFL students in Israel that make some serious semantic errors in their understanding of the F. Scott Fitzgerald story "Bernice Bobs Her Hair." Since the Israeli students were not familiar with practices reflecting the United States culture, they missed many nuances of the story, resulting in an incorrect comprehension of the story. In some cases, the Israeli students interpreted the expression of agreement "be glad to" as an imperative form. Bensoussan concluded that, because of cultural differences in 
the structure of the story and the characters actions, understanding was blocked "even when the words and syntax were familiar" (p. 402). The students were understanding the words, but the locution and pragmatic features of the dialog interchanges remained beyond the comprehension of these L2 students.

These differences between L1 and L2 reading were highlighted by Yorio (as cited in Omaggio, 1979), who pointed out that (1) the L2 reader's knowledge of the text differs from the knowledge of the native speaker, (2) inferring strategies are hindered by imperfect knowledge of the language, (3) associations are more difficult given the unfamiliarity of the experience, (4) previously decoded cues are difficult to remember due to the large amount of new information being acquired, and (5) the native language causes interference. (Yorio, 1971; as cited in Omaggio) There are several kinds of information that the computer can provide to alleviate these difficulties. The computer can provide background knowledge in the forms of sounds, pictures, text, and video to alleviate the first difficulty. The computer can also provide linguistic information that the students may have forgotten, as well as guiding the student toward more appropriate information cues. A note-taking component would allow the students to note relevant cues while still attending to the reading task.

Learners incorrectly assume that they need to understand each word in a foreign language passage (Aspatore, 1984), even though they may not necessarily need to understand each word in a native-language passage for comprehension. Thus, the role of the teacher in this instance is to encourage the students to use 
strategies to infer the meanings of unfamiliar words. Loew (1984) also recommends that L2 instructors emphasize a "global approach over reading isolated words or sentences" (Loew, p. 301). This global approach is more like the native-language interaction between reader and text.

\section{Background Knowledge and L2 Reading Comprehension}

In an L2 reading situation, background knowledge obtained in one language and culture can transfer to the L2 reading task. Levine and Haus (1985) found that the learners of Spanish who had high prior knowledge of baseball were better able to understand a Spanish passage about a baseball game than learners who had the same ability in Spanish, but a lower level of baseball knowledge. These differences were true both for textually explicit items (directly stated) and textually implicit items (implied by the context). Lee (1986a) found that students comprehended L2 passages about a familiar topic (washing clothes) better than passages about an unfamiliar topic (serenading via balloons). This finding underscores the effect of background knowledge, regardless of culture. By allowing students to activate their prior knowledge of a topic (Melendez \& Pritchard, 1985) and correcting background knowledge that may be incorrect or misleading (Woloshyn et al., 1994), instructors can develop reading strategies that will encourage students to infer the meanings of words by applying their existing knowledge to the current reading task, and to know when they should look up vocabulary. 
In order to combat this kind of cultural misunderstanding, many researchers have recommended a variety of locutionary strategies to help readers understand misconceptions in their existing knowledge that would interfere with their understanding of the text. Woloshyn et al. (1994) found that a refutational statement such as "although some people think that the light of the sun is only red and yellow, it is made of every different color including blue and violet" ( $p$. 79) help L1 readers to understand misconceptions in their existing knowledge, and further aid them in recalling information that is inconsistent with their prior knowledge. It follows that the same strategy of targeting the existing knowledge that may be inaccurate so that it can be refuted and will not cause misunderstandings will also prove helpful to L2 learners.

\section{Readability}

The use of formulas to determine readability has been long a factor in both English and Spanish texts. (Gray \& Leary, 1935; Spaulding, 1956) Readability formulas have various applications in education, varying from student issues to research issues. Student issues include interest, comprehension, and time on task. When students read passages that are within their level as determined by a readability analysis, the students will have higher reading comprehension and fewer oral errors (Fry, 1987). These students will also perform better on a cloze test and spend more time reading (Fry).

Readability analyses are also useful in educational research settings. Through the use of readability analyses, researchers have an objective control 
over the difficulty of the reading passages (Fry, 1987). Subjective teacher judgments are not as reliable as an objective formula, since they can tend to vary. (Vari-Cartier, 1981).

One of the most commonly-used readability analyses is the Fry readability formula (Vari-Cartier, 1981; Fry, 1987; Leu \& Kinzer, 1999; Crawford, 1984) due to its ease of use and its applicability across grade levels. (Leu \& Kinzer; Crawford) Issues contributing to the ease of use of the Fry formula is the lack of complex word lists (Leu \& Kinzer) and the lack of complex mathematical procedures (Leu \& Kinzer). Fry formula results correlate highly with other, more complex formulas as well (Crawford).

The Fry graph, or variations thereof, has also been used to estimate the readability of materials written in non-English languages, generally Spanish. (Crawford, 1984; Vari-Cartier, 1981; Gilliam et al., 1980). These studies used regression analyses to arrive at a readability formula appropriate for the evaluation of materials written in Spanish. Crawford's and Gilliam et al.'s formulas targeted material written for the elementary level. Vari-Cartier targeted advanced materials for the formula, and developed the Fry Readability Adaptation for Spanish Evaluation (FRASE), which is applicable across various levels of the Spanish L2 learner. Vari-Cartier also provided evidence of a high level of correlation among the FRASE readability analyses and cloze tests, the Spaulding readability formula, subjective teacher judgments of level, and multiple-choice test scores. 


\section{Recall Protocol}

Once students have read a text, they cannot be said to have comprehended it until they have processed the text and are able to incorporate it into existing knowledge and interact with it. The readers must assimilate or accommodate the text to enter it into their personal schema before comprehension can truly occur. (Davis, 1992; Melendez \& Pritchard, 1985)

But how can the instructor be certain that this processing has occurred? Probably the most important way is using the recall protocol technique. In this technique, readers write all they can remember of what they have read. This has the advantage of being entirely constructed by the reader, and so is not colored by the instructors cues (as in cued recall) or questions (as in traditional question/answer formats). Recall protocols should be written in the native language (L1) to ensure that production skills are not confounding the readers recall and comprehension. (Davis, 1992; Lee, 1986b). Lee found that L2 learners recall significantly more information in the native language than in the target language, indicating that if recall protocols are intended to measure true recall, native language recall is more indicative of what the learners actually recall, rather than what they are able to recall and report in the target language.

$$
\text { Computers, Schema Theory and L2 Reading }
$$

The logical approach for L2 teachers who are concerned about their students' reading comprehension is to find a way to inform students of cultural knowledge and to fill possible gaps in the students' schemata. The concept of 
schemata belongs to a theory called schema theory. Essentially, schema theory is the idea that "when people encounter new information, they attempt to understand it by fitting it into what they already know about the world, schemata being the mental structures that store peoples' knowledge in memory." (Melendez \& Pritchard, 1985, p. 400) Traditional methods for activating schema have been prereading activities and postreading activities that familiarize students with unfamiliar material as well as help them to activate relevant schemata so that they may assimilate the new information into existing schemata. However, the difficulty is that students may not see this prereading information as related to the text. A preferable presentation of this information would be concurrent with the text (Melendez \& Pritchard), so that the students can access information and clarification if and when they are having difficulty activating relevant schemata. This kind of access to information features a higher degree of learner control, which has not generally been a feature of reading programs in general or of computer-assisted language learning (CALL) in particular (Dalgish, 1987).

Since these cultural background variables have an influence on L2 reading comprehension, it is necessary to consider the best ways to communicate the cultural and linguistic information that students need in the most efficient manner possible. The computer's ability to provide students with information of various types on demand makes it a logical choice for this purpose. However, the danger is that reading program designers will make an electronic page-turner, 
and not capitalize on the strengths of the computer in providing information and access to information that is not possible with a conventional text. It is assumed that students can learn to read using the computer in the same ways that they learn to read using printed materials. According to Garrett (1991), this way of thinking "ignores the computer's ability to offer learners ways of learning to read that go far beyond simple decoding." (p. 5) Reading, as has been stated earlier, is far more than understanding of each of the individual words that makes up a text. Such other reading strategies as inferencing, planning, and assimilating information within a contextual framework allow the full capabilities of the computer to be used in helping students read (Garrett, 1991).

\section{Use of Aids in Computer-Assisted Reading}

Some research into L1 reading has been helpful in seeing ways in which the computer can be useful in L2 reading. Reinking and Schreiner (1985) used the computer to deliver textual information about the reading that is not available in traditional texts, such as definitions of key vocabulary, a simpler version of the story, background information, and structural cues. They found that students who had access to all these options comprehended the passage more than students who had access to no cues or access to some of the cues. This finding is echoed by Aweiss (1994-95) with L2 learners. In this study, learners had access to additional information regarding vocabulary, verb conjugation, and background information. The learners who had access to these supports had higher comprehension as measured by a recall protocol in the native language. Both sets 
of researchers hypothesize that the computer can manage the readers' interactions with the text, leading to greater metacognition of reading strategies that are sometimes ignored (Aweiss, 1994-95; Reinking \& Schreiner 1985). Mayer's $(1994,1997)$ work supports these theories. In these studies, students worked with multimedia packages explaining various engineering concepts. Students who had worked with the multimedia elements were better able to apply the problem-solving strategies that they had learned to novel situations than were students who only had access to textual explanations. Students who heard a narration explaining the process they saw animated had more gains in problem-solving skills than students who read a textual explanation about the animation (Mayer, 1997). The explanation for this occurrence was that hearing the narration enabled students to obtain input from two sources, visual and auditory, thus supporting Paivio's (1986) dual coding theory. Since reading strategies such as inferencing and prediction share similarities with problem solving, it follows that presentation of information using the auditory channel will also lead to better offline reading skills.

\section{Types of Multimedia Aids in CALL}

L2 studies of interest have examined the effectiveness of various types of textual clarifications. A treatment which places the reading and the vocabulary within a context is consistently better than a treatment that only provides a definition or other grammatical information. (Aweiss, 1994-5; Chun \& Plass, 1996b; Kang \& Dennis, 1995; Liu, 1995), although a text gloss, consisting of a 
parenthetical textual explanation of unfamiliar words or concepts, can also be useful in helping L2 learners to understand the reading passage (Davis, 1989). Rather than distracting the reader, the gloss can clarify meaning and assist in reading comprehension.

Studies regarding multimedia annotations of words or reading passages have also determined that there are other issues at play here. Some types of annotations are correlated with higher rates of recall for the annotated item, which implies that some forms of annotations are more effective than others (Chun \& Plass, 1996b; Kang \& Dennis, 1995). Aweiss (1994-5) found that reading comprehension for Arabic as a foreign language was enhanced by the use of computer-mediated supports, including verb conjugation, background information, and glossary supports. The students who had access to these supports scored significantly higher on recall protocols than the students who had no such access. Kang and Dennis also found that foreign language learners who could access a definition during the practice scored higher than those who could not. They also found a significant effect for other types of media on vocabulary acquisition. While there was no significant picture effect, there was a significant effect for the use of contextual aids, which combined the use of visual (picture), aural (sound), and sentence contexts. The richness of the context condition appears to enhance vocabulary acquisition. Liu (1995) found similar results. In this study, ESL learners were significantly more likely to access the video and the relationship contextual aids when the words were unfamiliar than 
when they were familiar. These two tools provided the most comprehensive contextual support. Liu found no significant relationship between the number of times students access the contextual aids and their achievement scores. This finding is in contrast with Aweiss' (1994-5) finding that students who accessed the contextual aids had lower comprehension scores, but echoes Hulstijn's (1993) and Chun and Plass' (1996b) findings. Chun and Plass found that items mentioned in the video advance organizer were more likely to appear in the students' recall protocols, indicating that video was an effective way of providing contextual information.

Hong (1997) found that learners of business Chinese were able to read faster and more effectively via a multimedia package than using conventional, text-based methods. Students using the multimedia package were able to read twice as quickly as students using the text-based method. Students using the multimedia package also scored much higher on the reading comprehension task than the other students. Hong attributes this effect largely to the glossing feature of the package, which facilitated the students' efforts in finding word definitions. Since Chinese characters can change meanings in the presence of other characters, it is important for the students to know the context of the character to determine the meaning of the word. The glossing feature isolated the relevant definition for the student, thereby causing the students to complete the reading task more quickly and with higher comprehension. This finding lends credence to Davis' (1989) suggestion to use hypertext glosses in L2 reading materials to 
allow the student to obtain as much context-specific information as necessary about the word or phrase in question.

\section{Multimedia CALL}

But the computer can do much more than simply offer textual clarifications. Especially with the advent of multimedia, the computer can be used to display images, video, and audio that can help students place information in context. One of these nontextual aids is the use of an audio version of the text (Aspatore, 1984; Garrett, 1991). Since students who are read to learn to read on their own more quickly than do students who are not read to, it follows that having an audio version of the text available to students allows them to receive the benefit of oral reading while not requiring that a live reader be present. Aspatore suggests that having an audiotaped version of the text can help students finish long texts without feeling bogged down by lack of understanding of each word. Mayer (1994) concurs with this belief and suggests that the coordination of narration and text is the most important part of an educational multimedia package. Hong cites the audio effect of the reading software her students used as a major contributing factor to their comprehension of a business Chinese text. Since there is no sound-spelling correspondence in Chinese, if students forget how a word or character is pronounced, they cannot use phonetic cues to determine the sound of the word. Hong stated that the students reported that such sounding reminded them of the meaning of the words if they temporarily were not able to recognize the written form (Hong). 
The same feature can be useful even for languages using the same alphabet, for very seldom are the same two letters pronounced exactly the same in two different languages.

Pictures as an aid to text comprehension have also been widely used. The research on this topic has had mixed results. Kang and Dennis (1995) incorporated pictures as one treatment for their study of vocabulary acquisition. They found that pictures did not help with the recall of vocabulary. However, they did find that the use of contextual cues affected increases in vocabulary retention and listening comprehension. Omaggio (1979) found that foreign language readers who looked at a picture before the reading task performed the highest on the recall task, while students who had no picture performed lowest. Interestingly, the use of a picture for native language readers had no effect, indicating that the use of pictures will be more helpful to those reading in a foreign language than those reading in their native language. (Omaggio, 1979)

The incorporation of video into L2 software has been greatly hailed by L2 researchers (Dalgish, 1987; Schwartz, 1995; Warshauer, 1997). However, research into the effectiveness of video use in the classroom has been mixed. Harmon and Dinsmore (1994) found that users disliked the use of a videodisk in a hypermedia environment because of confusion and distraction from the task at hand. Liu and Reed (1995) found that field dependent learners accessed more video than did field independent learners, thus implying that video is more beneficial for field dependent learners than for field independent learners. They hypothesize that 
the video segments allowed field dependent leaners to put the target vocabulary into a context, as they rely heavily on context of material in learning. Chun and Plass (1996b), who used a video segment as an advance organizer for their reading program CyberBuch, found that units presented in the video advance organizer were significantly more likely to be mentioned in recall protocols than units that were not mentioned. Hence, they conclude that a video advance organizer aids in comprehension of $\mathrm{L} 2$ reading.

\section{Computer-Assisted Reading}

One difference between the Kang and Dennis (1995) study and other studies (Chun \& Plass, 1996b; Mayer \& Sims, 1994) is that Kang and Dennis were examining vocabulary acquisition, rather than reading comprehension. Reading, as noted before, involves much more than simple vocabulary recognition and decoding. Mayer and Sims found that presenting verbal and visual information concurrently did lead to higher reading comprehension among L1 readers. Similarly, Chun and Plass found a significant effect of dual presentation of information on inclusion of this information in recall protocols. This finding suggests that words annotated both visually and verbally are better remembered, leading to higher reading comprehension levels and better processing of information. Findings in these studies lend credence to Paivio's (1986) dual coding theory which states that verbal and visual information presented concurrently will be better remembered than visual or verbal information presented alone. 


\section{Individual Differences and Language Learning}

Affective characteristics that can contribute to successful language learning is of great interest to language teachers (Carroll, 1963; Brown, 1977). The cognitive control of field independence and field dependence is especially important (Witkin et al., 1977). Field independent students tend to seek out information that they find relevant or interesting, while field dependent students accept the existing structure of information presented. Field independent students excel at restructuring information, while field dependent students excel at seeing a particular situation as a coherent whole. Preliminary research has found that field independent learners are generally more successful at language learning than are field dependent learners (Carter, 1988; Chapelle \& Green, 1992; Chapelle \& Jamieson, 1986; Chapelle \& Roberts, 1986; Hansen \& Stansfield, 1982). Varying explanations exist for this difference. Since field independent learners excel at forming rule-based strategies (Witkin et al.), it is hypothesized that these learners excel at rule learning and rote memorization, traditional methods often used in teaching foreign languages. The research mentioned earlier seems to support this theory. Chapelle and Jamieson stated that field independent learners are more likely to profit from using CALL, but that they prefer it less than field dependent students do. Brown suggests that field dependent students are more likely to excel at communicative tasks given their desire for context and attention to social cues. However, research does not support this hypothesis (Carter; Chapelle \& Green; Hansen \& Stansfield). Even in communicative tasks in 
which field dependent students are theorized to excel, given their social orientation, field independent students still outperform field dependent students (Carter; Chapelle \& Green; Hansen \& Stansfield).

However, it is not necessary for students to be field independent in order to be successful language learners. Liu and Reed (1995) found that field independent and field dependent students learned vocabulary equally well by using a contextually rich hypermedia program. This is in direct conflict with Chapelle and Jamieson's (1986) findings that CALL did not benefit FD students. It is possible that the advancements in hypermedia technology allows software to have more flexibility and be more responsive to the students individual differences than the linear PLATO software used in the Chapelle and Jamieson study. It is also possible that field dependent students can actually surpass field independent students in some areas which are difficult to assess using current assessment methods. Most second-language acquisition research about FD/FI has used measurements that favor FI students. Hansen and Stansfield (1982) used performance on a cloze test and performance on a final examination (consisting of grammatical manipulations) to measure L2 proficiency. The cloze test used consisted of a passage with every fifth word deleted. Students were then instructed to fill in the missing spaces. This is a task at which analytic students would be expected to excel, because the context required of this task is on the phrase level rather than on the level of the entire passage. Both the cloze test and the grammatical final examination would tend to favor more analytic 
students who are comfortable applying rules to a situation, such as FI learners, for these measures require the students to isolate the relevant information from other information which may be distracting, a task at which FI students excel (Witkin et al., 1977). In fact, Chapelle and Green (1992) found that cloze test scores were significantly higher among FI native speakers than FD native speakers, indicating that the cloze test does indeed favor FI students, regardless of language ability.

In none of these studies was reading comprehension and/or recall used as a factor to measure language learning, so there is no empirical evidence to suggest that either group of students would outperform the other. It is possible to predict that either type of learner would excel. If students approach the task as a decoding task, FI students would be expected to excel, since they are the ones best able to extract relevant information and re-order it based upon internal frames of reference (Witkin et al., 1977). However, if reading is considered to be a process by which the reader integrates the new information into an existing schema, as suggested by the schema theory of reading (Melendez \& Pritchard, 1985), FD students would be expected to excel, since they are best able to understand information holistically (Witkin et al.). Since no empirical research exists on the role of FD/FI in reading success in L1 or L2, there is no empirical data to support one theory over the other. 


\section{Summary}

As can be seen from the preceding research, foreign language readers have much more information to manage than simply remembering the meanings of unfamiliar words and recognizing grammatical structures that may diverge from grammatical constructions in their first language. L2 readers are also reading about a foreign culture and may encounter occurrences which may have no correspondence to their background knowledge. Furthermore, some information is very difficult to represent via textual clarifications in the traditional gloss format. For example, it is much more straightforward to present a picture of a zebra than to explain in words that a zebra is a horselike animal with black and white stripes that lives in the grasslands of Africa. A picture of a zebra in its native habitat would be much more effective in conveying the information than the textual clarification. In much the same way, audio and video can provide other cues that would enhance understanding in the L2 reader.

However, the question of what kind of information should be included remains. This is where the research on cognitive controls (FD/FI) can be helpful. Of several learner characteristics identified in the research, FD/FI has been shown to be related to language learning more strongly than other factors (Chapelle \& Roberts, 1986). Students having field dependent and field independent cognitive controls also have different preferred modes of processing information, although each can be equally successful at learning a foreign 
language (Liu, 1995). By incorporating a variety of multimedia aids in the reading courseware, software designers can be assured that individuals with each cognitive control can use different elements of the courseware to learn the language equally well. 
CHAPTER III: METHODS

Participants

The participants were 11 native English-speaking students enrolled in Spanish 104 at West Virginia University. The mean age was 19.45. The mean number of years that they had studied Spanish was 5.8. Five of the students were majoring in either Spanish or Spanish education. Of the others, three were majoring in psychology, one in business, one in exercise physiology, one in speech pathology and audiology, and one in international studies. (One participant indicated a double major in Spanish and psychology and was counted for each major.) To guard against differences due to familiarity with Hispanic cultures, none of the students had lived in a Spanish-speaking country. Spanish 104 is the second course beyond the intermediate sequence, with emphasis on reading and writing. Participation in the research study was voluntary.

\section{Setting}

The setting was a PC computer lab equipped with 15 Windows NT computers. The program was loaded on the individual computers. (See Appendix A for the text of the reading courseware.) Participants were allotted 30 minutes to complete the research in a group setting.

\section{Materials}

The students read the 413-word passage via a program created in HyperStudio, using design principles outlined by Hannafin and Peck (1988). The 
text was subdivided into six screens of text. The multimedia aids consisted of 24 vocabulary glosses, six photographs of Mayan architecture, and a native speaker of Spanish reading the text. The vocabulary terms were indicated by blue text that the students could click on to access an English explanation of the word. A button indicated the option to see a picture related to the text on the page, and another button indicated the option to hear a native speaker read the text. The subject of the reading passage was Mayan architecture. The reading was selected from Eugenio Chang-Rodríguez' book Latinoamérica: Su civilización y cultura, an advanced text about Latin American culture. The passage was chosen from the section “La arquitectura precolombina en Mesoamérica," which describes preColumbian architecture in Mesoamerica, highlighting the architecture of the Aztecs and the Maya. To ensure consistency of theme, sentences referring to Aztec architecture were cut from the passage, leaving only the information about the Maya. Although information relating to the Aztec architecture was eliminated from the passage, the passage was not adapted for meaning or for ease of reading to ensure an authentic reading experience. The topic of architecture was chosen to emphasize the lack of background knowledge the students are likely to have about the subject matter, given the fact that none of the students are majoring in architecture. The Aztec information was excluded based on the university's travel programs to the Valley of Mexico, since students who had been participants in this program might have had more experience with Aztec architecture than other students who had not participated in this program. 
The multimedia aids were chosen to fill the gaps in the students' prior knowledge. These gaps include unfamiliar vocabulary, unknown pronunciation of words, and unfamiliarity with architectural styles and climate in Mesoamerica. The passage's readability is at the advanced level, as determined by applying the Fry Readability Adaptation for Spanish Evaluation (FRASE) (Vari-Cartier, 1981) to the passage. The FRASE was chosen due to its appropriateness for use at advanced level of L2 Spanish reading and its high correlation with other measures of readability (Vari-Cartier, 1981). The passage was supplemented by audio material (a native speaker reading the passage) (Hong, 1997) , pictures (pictures of vocabulary that may be unfamiliar to the students and examples of unfamiliar architectural styles) (Omaggio, 1979), and explanations in English of unfamiliar vocabulary. In total, there were six audio readings, six pictures of Maya architecture, and 24 vocabulary translations that participants could access.

\section{Measurements}

\section{Independent Variable}

\section{Group Embedded Figures Test (GEFT)}

During a class session prior to the treatment, students completed a questionnaire with demographic data (see Appendix B). This questionnaire also requested that students self-report their knowledge of architecture. They were then administered the Group Embedded Figures Test (GEFT) (Witkin et. al., 1971) to determine field dependence/field independence. The GEFT is a groupadministered, 25-item, timed ( 2 minutes for the first part, and five minutes for 
the second and third parts) task in which participants are shown a simple figure, and then trace the simple figure that is embedded in a more complex figure. Ability to consistently trace the simple figure embedded in the complex figure indicates a high level of field independence. Since the first seven items on the GEFT are not scored, the maximum score (indicating the highest level of field indepenence) is 18. The GEFT has a reliability of .82 (Witkin et al., 1971), and convergent validity has been established (Goodenough \& Karp, 1961; Witkin et al., 1971). See Appendix C for a sample figure from the GEFT.

\section{Dependent Variables}

\section{$\underline{\text { Recall Protocol }}$}

A recall protocol was administered after the reading activity to measure reading comprehension. The recall protocol consisted of verbal and written instructions of the researcher that the participants should write everything they could recall about the story from the reading program. The participants wrote the recalls in English to ensure that reading comprehension, and not production skills in the native language, were being measured. Lee (1986) found that foreign language learners relate more information on the recall task when recalls are written in the native language. Two readers independently analyzed the passage to identify idea units, defining an idea unit as a group of related words expressing a concept, such as a phrase or clause. They identified 42 idea units present in the passage. The readers adjusted discrepancies in consultation with the each other until the agreement was at the one hundred percent level. See 
Appendix A for the text of the reading passage divided into idea units. The readers then independently analyzed the participants' recall protocols and marked each idea unit present in the recall. The readers met to discuss the results of the scoring, and were in agreement at the .997 level.

\section{$\underline{\text { Multimedia Aid Access }}$}

The reading program recorded participants' mouseclicks. The mouseclicks were tabulated and separated according to type of multimedia aid accessed (text, sound, or picture).

\section{Procedures}

During a regular class meeting, the participants completed the questionnaire of demographic data (see Appendix B) and were administered the GEFT. At another session in the computer lab, the participants were shown how to operate the reading courseware, including which icons indicate which type of contextual aid. Participants were encouraged to experiment with a sample section of the courseware to ensure that all students understood how to use the courseware and that the equipment was functioning properly. In the one instance of equipment difficulties, the participant was moved to another computer which functioned correctly during this practice session. Participants were informed that they could access any or all or none of the multimedia aids. Participants then were given 15 minutes to use the courseware to read the passage. They were able to choose as many or as few aids as they felt necessary. All participants finished well within the prescribed 15 minutes. After the reading 
session, the students were instructed to write, in English, everything they could remember about the story.

\section{Research Design}

The reading package tabulated students' mouseclicks. The data were analyzed using Statview 5.

To answer the first research question: "What is the effect of cognitive control (FD/FI) on use of multimedia annotations?" the students' cognitive control and number of mouseclicks of each annotation type were analyzed. Three unpaired t-tests were calculated, using cognitive control as the independent variable and type of multimedia aid (text, sound, picture) as the dependent measures. To answer the second research question, "What is the effect of cognitive control (FD/FI) on reading comprehension?" a two-tailed, unpaired ttest was calculated, using cognitive control as the independent variable and recall protocol score as the dependent variable. 


\section{CHAPTER FOUR: ANALYSIS}

The sample consisted of 11 participants. Of these, five were classified as field independent and six as field dependent based on the norms of the GEFT. (Witkin et al. 1971). There was a difference in the number of times that the students having varying cognitive controls accessed the multimedia reading supports, with the field dependent students accessing the multimedia aids many more times than the field independent students. The field independent students selected the vocabulary supports a total of 45 times (mean 9.00), the sound supports a total of nine times (mean 1.80), and the picture supports a total of nine times (mean 1.80), for a grand total of 63 mouseclicks (mean 12.6). The field dependent students selected the vocabulary supports a total of 94 times (mean 15.67), the sound supports a total of 11 times (mean 1.83), and the picture supports a total of 24 times (mean 4.00) for a grand total of 129 mouseclicks (mean 21.5). See Table 1 for a summary.

Table 1: Mean Multimedia Accesses by Cognitive Control

\begin{tabular}{l|rrrr} 
& Vocabulary & Sound & Picture & Total \\
\hline Field Dependent $(n=6)$ & 94 (mean 15.67) & 11 (mean 1.83) & 24 (mean 4.00) & 129 (mean 21.50) \\
Field Independent $(n=5)$ & 45 (mean 9) & 9 (mean 1.80) & 9 (mean 1.80) & 63 (mean 12.60)
\end{tabular}

Although the field dependent students accessed the multimedia supports many more times than the field independent students, there was not a statistically 
significant difference between the two groups in the number of supports accessed. The field dependent students' greater access of the multimedia supports is to be expected, since field dependent students have a more global approach to understanding than field independent students, who tend to focus more closely on the goal at hand (Witkin et al. 1977). Previous studies have also found that field dependent students have accessed more video and picture aids than field independent students (Liu 1992). It is interesting to note that there was one field independent student who accessed none of the supports at all, and one field independent student who accessed only one support, a picture. These two students also had the highest GEFT scores of the sample, and so were the most strongly field independent. Apparently these two students did not think the supports would aid their understanding, and thus ignored them. (These students did understand how to use the equipment, and the equipment was working properly in both cases.)

In contrast, the most highly field dependent students (indicated by the lowest scores on the GEFT) were much more likely to access the multimedia aids. The most highly field dependent student (GEFT score $=5$ ) accessed every picture except one (5 picture accesses). This student only accessed the sound option once, but relied heavily on the vocabulary tool, for a total of 19 accesses. The student with the next lowest GEFT score (GEFT score=7), however, showed different patterns of access. This student accessed the vocabulary support only three times, but accessed half of the sounds (3 sound accesses). This student 
showed more similarity to the other FD student in accessing the picture supports (4 picture accesses).

To answer the first research question, "What is the effect of cognitive control (FD/FI) on use of multimedia annotations?" , three unpaired t-tests were calculated, using the participants' cognitive control as the independent variable and the number of mouseclicks per category as the dependent variable. (See Tables 2-5.) For the t-test relating cognitive control to vocabulary accesses, there was no significant difference in the number of times that field independent and field dependent students accessed the available vocabulary definitions ( $\mathrm{p}=.4976)$. See Table 2.

Table 2: T-test Results for Vocabulary Accesses

\begin{tabular}{crcrrrr}
\hline \multicolumn{2}{c}{ Field Dependent } & \multicolumn{3}{c}{ Field Independent } \\
\multicolumn{3}{c}{$(\mathrm{n}=6)$} & \multicolumn{2}{c}{$(\mathrm{n}=5)$} \\
$\mathrm{M}$ & $\mathrm{SD}$ & $\mathrm{M}$ & $\mathrm{SD}$ & $\mathrm{t}$ & $\mathrm{p}$ \\
15.67 & 10.152 & 9.00 & 9.110 & 1.135 & $\mathrm{NS}$ \\
\hline
\end{tabular}

For the $\mathrm{t}$-test relating cognitive control to sound accesses, there was no significant difference in the number of times that field independent and field 
dependent students accessed the available sound of a native speaker reading the text aloud $(\mathrm{p}=.9885)$. See Table 3 .

Table 3: T-test Results for Sound Accesses

\begin{tabular}{crcrrr}
\hline \multicolumn{2}{c}{ Field Dependent } & \multicolumn{3}{c}{ Field Independent } \\
\cline { 1 - 3 }$(\mathrm{n}=6)$ & \multicolumn{3}{c}{$(\mathrm{n}=5)$} & & \\
$\mathrm{M}$ & $\mathrm{SD}$ & $\mathrm{M}$ & $\mathrm{SD}$ & $\mathrm{t}$ & $\mathrm{p}$ \\
1.83 & 1.835 & 1.80 & 2.168 & .028 & $\mathrm{NS}$ \\
\hline
\end{tabular}

For the t-test relating cognitive control to picture accesses, there was no significant difference in the number of times that field independent and field dependent students accessed the available photographs ( $\mathrm{p}=.1379)$. See Table 4 .

Table 4: T-test Results for Picture Accesses

\begin{tabular}{crcrrrr}
\hline \multicolumn{2}{c}{ Field Dependent } & \multicolumn{3}{c}{ Field Independent } \\
\cline { 1 - 3 }$(\mathrm{n}=6)$ & \multicolumn{2}{c}{$(\mathrm{n}=5)$} & & \\
$\mathrm{M}$ & $\mathrm{SD}$ & $\mathrm{M}$ & $\mathrm{SD}$ & $\mathrm{t}$ & $\mathrm{p}$ \\
4.00 & 2.098 & 1.80 & 2.387 & 1.628 & $\mathrm{NS}$ \\
\hline
\end{tabular}


These tests indicated that the students' learning style was not a significant predictor of their use of any of the multimedia aids.

Since there was no statistically significant difference in the usage of any of the indicated supports, I conducted a fourth unpaired t-test, using cognitive control of the participants as the independent variable and total number of mouseclicks for all aids combined as the dependent variable. This analysis also revealed no statistically significant differences. See Table 5.

Table 5: T-test Results for Total Multimedia Aid Accesses

\begin{tabular}{crcrrrr}
\hline \multicolumn{2}{c}{ Field Dependent } & \multicolumn{3}{c}{ Field Independent } \\
\cline { 1 - 3 }$(\mathrm{n}=6)$ & \multicolumn{3}{c}{$(\mathrm{n}=5)$} \\
$\mathrm{M}$ & $\mathrm{SD}$ & $\mathrm{M}$ & $\mathrm{SD}$ & $\mathrm{t}$ & $\mathrm{p}$ \\
21.50 & 10.932 & 12.60 & 12.542 & 1.259 & $\mathrm{NS}$ \\
\hline
\end{tabular}

To answer the second research question, "What is the effect of student's cognitive control on reading comprehension as indicated by recall protocol?" the researcher enlisted the assistance of a secondary researcher. The two researchers independently read the passage and divided it into idea units, as described by Lee (1986). They then discussed this division until they agreed at the 100 percent level. (See Appendix A for the division of the reading passage into idea units.) 
The two readers independently read the students' recall protocols and marked the idea units that each participant indicated in the recall protocol. Interrater reliability for this task was .997 . In each case of disagreement, there was one point separating the two scores. For the purposes of data analysis, the mean of the two ratings was used when a discrepancy was found. The mean of all recall protocol scores was 7.818, with a standard deviation of 3.69. There was one outlier, who recalled 18 idea units. This outlier might have affected the results. A two-tailed, unpaired t-test was calculated, showing no statistically significant difference between the two groups. (See Table 6)

Table 6: T-test results for Recall

\begin{tabular}{crcrrrr}
\hline \multicolumn{2}{c}{ Field Dependent } & \multicolumn{3}{c}{ Field Independent } \\
\cline { 1 - 3 }$(\mathrm{n}=6)$ & \multicolumn{3}{c}{$(\mathrm{n}=5)$} \\
$\mathrm{M}$ & $\mathrm{SD}$ & $\mathrm{M}$ & $\mathrm{SD}$ & $\mathrm{t}$ & $\mathrm{p}$ \\
9.083 & 4.499 & 6.300 & 1.857 & 1.286 & $\mathrm{NS}$ \\
\hline
\end{tabular}

Part of an explanation for this result may be the unusually high variance (20.242) in the FD group, caused by the aforementioned outlier. As I suspected that the outlier might have caused the lack of significance, I conducted a second unpaired t-test, this time ignoring the outlier. While the results of this analysis produced a much smaller variance (1.45), there was still no statistically significant difference between the two groups. See Table 7. 
Table 7: T-test Results for Recall (excluding outlier)

\begin{tabular}{|c|c|c|c|c|c|}
\hline \multicolumn{2}{|c|}{ Field Dependent } & \multicolumn{2}{|c|}{ Field Independent } & & \\
\hline$(\mathrm{n}$ & & $(n$ & & & \\
\hline M & SD & M & SD & $\mathrm{t}$ & $\mathrm{p}$ \\
\hline 7.300 & 1.204 & 6.300 & 1.857 & 1.010 & NS \\
\hline
\end{tabular}




\section{CHAPTER 5: CONCLUSIONS}

\section{Discussion of Findings}

This research found no significant differences between field independent and field dependent L2 learners, either in patterns of access of multimedia supports or in reading comprehension as measured by a recall protocol. FI participants and FD students showed statistically insignificant differences in patterns of access to the multimedia aids, as well as a statistically insignificant difference in recall protocol scores. In all cases except for two, the participants chose to access the multimedia aids more than once, indicating that if these aids are available, the participants will usually use them.

The fact that FD and FI students show similar access patterns is puzzling, considering that other research has indicated that there are differences in access pattens in a vocabulary-learning task. While on the surface there did appear to be a difference in the amounts of reading supports accessed, the statistical analysis revealed no statistically significant differences. Since the two participants who were most highly field independent accessed the fewest number of reading supports, this result would appear to indicate that highly FI students saw the aids as a distraction from their goal of reading the passage. FD students, on the other hand, tended to access more aids than did the FI students, but this is still an anecdotal observation. Future research with a larger $n$ might reveal some of these apparent differences. 
One possible explanation for the differences is that, while the norms of the GEFT were used, in some cases there was little difference between the GEFT scores for students on the upper edge of field dependence and the lower edge of field independence. A median split mode of analysis might reveal some differences between the two groups, but due to the small $\mathrm{n}$ that analysis would not be appropriate in this case. Until this research is replicated with a larger n, we simply will not know.

The differences among the two groups in patterns of multimedia access appeared to be different, but a statistical analysis failed to reveal any significant differences. This nonsignificant result could be related to the small sample size. As sample size increases, so does statistical power. The lack of power may be a reason that the statistical analysis failed to reveal apparent differences. Replication of this study with a larger $\mathrm{n}$ might well reveal significance in patterns of access between field dependent and field independent students.

As indicated before, other studies have shown that FD and FI students prefer to access different tools in the vocabulary learning task (Liu 1992). It is logical that since reading for meaning is quite a different task from the learning of discrete vocabulary terms, L2 learners may employ different strategies when engaged in a reading task than they do when they are learning vocabulary.

Other possible sources of discrepancy are the levels of experience and proficiency with Spanish and levels of expertise relating to architecture. However, all of the participants indicated a novice level of knowledge of 
architecture. In all cases, levels of self-reported knowledge of Latin American music and art (the distractor items) was higher than the self-reported knowledge of architecture. In light of these self-reported areas of knowledge, differences in knowledge of architecture is probably not the source of the discrepancy.

The levels of Spanish knowledge for the participants was also very similar, given that they had similar prior experience with Spanish. They had studied Spanish about the same length of time, and none reported significant time living in a native Spanish-speaking country. This discounts the possibility of levels of prior knowledge of Spanish having some kind of confounding effect.

The lack of significance in the second research question is heartening for foreign language teachers, for it indicates that FI learners are not the only successful types of language learners. FD students, at least in the reading arena, can be just as successful as FI students, which is in opposition to findings in other research settings. (Hansen \& Stansfield 1982, Chapelle \& Jamieson 1986, Carter 1988, Chapelle \& Green 1992) However, we must be cautious with this claim, given the small sample size tested.

Earlier studies (Chun \& Plass 1996a, Chun \& Plass 1996b) have indicated that these types of multimedia reading aids do aid in the understanding of novice readers. It is possible that by the time the students have reached this intermediate level of L2 knowledge, their reading patterns are established. Perhaps this type of multimedia aid is most useful when students are first learning to read in a foreign language, and multimedia aids are superfluous at 
this level. Since Spanish 104 is not a university-wide requirement, students who do not have a particular interest in the language or talent in language learning are not likely to enroll in this class. In fact, almost half of the participants had chosen Spanish as a major area of study, indicating a high interest in the study of the language. One must be cautious in suggesting that these students had a higher level of motivation than other students, for other researchers (Carroll, 1963; Chapelle \& Roberts, 1986) have found no relationship between motivation and success in the foreign language classroom. Chapelle and Roberts used a subscale of the Attitudes and Motivation Test Battery to measure motivation, while Carroll summarized previous research.

\section{Suggestions for Future Research}

Suggestions for future research include replication of the study with a larger $\mathrm{n}$ to enhance the statistical power of the study. The study was a limited exposure to the reading courseware, consisting of less than an hour of student interaction with the multimedia reading courseware supports. It is possible that the participants in this study had not used CALL before, in any fashion, and thus were curious about its potential. This factor could explain the tendency of both field dependent and field independent to access the aids. If the study is repeated over a longer period of time, differences might reveal themselves once the novelty has worn off. A practice reading was included in this study, both to counterbalance the novelty effect and to ensure that the equipment was functioning properly before data collection commenced. It is possible that a 
longer practice session, or more sessions using a similar type of courseware, might well yield different results.

Since not every idea unit had a corresponding link, an interesting study would examine whether the idea units exemplified by the links would be more likely to be recalled by participants. Other reseearch has shown that items mentioned in a video advance organizer would be more likely to be mentioned in a recall protocol (Chun \& Plass, 1996a), but has not extended this to other kinds of multimedia aids.

Another possible source of the wide variance in the multimedia accesses might be the amount of prior computer experience of the students. If there was a difference in the amount of computer experience in the students, the students without prior experience might be curious about the capabilities of the computer and might be inclined to use more of the tools to see how each of the tools functioned and to examine the capabilities of the computer. A future study might examine the relationship of prior computer experience with the usage of the multimedia tools.

Computer anxiety is another factor that could be addressed in future research. Students with a high level of computer anxiety might be unwilling to use the tools that are present. Levels of computer anxiety usually have an inverse relationship with computer experience: the more experience students have with computers, the more comfortable they are while they are using the computers, and the more their computer anxiety decreases. An interesting study would 
examine the relationship of computer anxiety with the number of multimedia aid accesses. Students with high levels of computer anxiety might well be reticent to use a computer to assist in their reading in a foreign language and might understand less of the passage than their peers with a lower level of computer anxiety. An interesting study would examine the relationship between the two factors of computer anxiety and cognitive control and the relationship of each with the number of recall units indicated on a recall protocol.

Another possibility for future research is to compare the reading recalls of three groups: a group given a reading passage in print, a group given the same passage in print on a computer screen, and a third group given the same passage together with multimedia aids . This study would reveal if there was an effect of the multimedia aids.

Another possible research topic would be to compare the recall results of native speakers and L2 learners to see if there is a significant difference between the two. With a reading as long as this one, it is unlikely that even native speakers would recall every idea unit, because it is not necessary to recall every detail of the reading in order to derive meaning from it (Lee 1986a).

\section{Summary and Conclusions}

The study found that, while there was no significant difference in the amount or type of multimedia aids advanced L2 readers accessed in a free environment, neither was there a significant difference in the amount of reading comprehension as measured by a recall protocol. The latter lack of significance is 
heartening for L2 teachers, for it suggests that FI and FD students are both capable of success in the advanced L2 reading classroom. In this free task, with one exception, the participants chose to access the multimedia aids to assist in their comprehension of the passage. It seems possible that the reading was too advanced for them to understand on their own, given the high difficulty level of readability of the passage. Given the high difficulty level of the passage and the fact that the majority of the students chose to access the multimedia aids, it seems possible that the participants were able to understand this advanced passage with the assistance of the multimedia aids. However, there is not a significant difference in the type of aids accessed by students having each cognitive control. In spite of this lack of significance, there were differences in the patterns of access between the two groups of learning styles. Replication of this study with a larger sample size might reveal differences that were not apparent during this study. 
APPENDIX A: TEXT OF READING PROGRAM DIVIDED INTO IDEA UNITS

(NOTE: Paragraphs indicate screen breaks and not actual paragraphs. Underlining indicates words that were linked to textual explanations.) $\underline{\text { La arquitectura precolombina en Mesoamérica }}$

Durante el período precolombino/, la arquitectura en el hemisferio

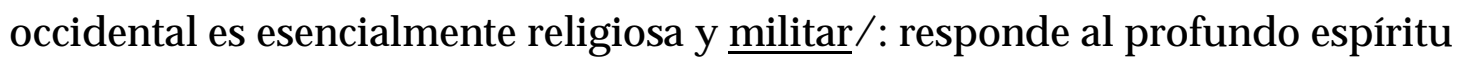
místico y bélico de sus habitantes. /Mientras que la arquitectura religiosa encuentra su máxima expresión en los templos, pirámides y centros de adoración/, la civil se concreta principalmente en levantar palacios gubernamentales./ En las antiguas culturas amerindias más avanzadas la arquitectura fue el arte por excelencia./ En la maya/, la arquitectura religiosa alcanzó un alto nivel de desarrollo./

La arquitectura maya, tan distintiva como la de cualquier civilización antigua/, tuvo variaciones determinadas por el espacio y el tiempo/; o sea, desarrolló variantes regionales durante las dos etapas de su historia/. Las mejores estructuras del período clásico se construyeron en Copán/, importante centro de estudio y observaciones astronómicas/. Ahí se levantaron las más perfectas pirámides truncadas. /

La maya aparentemente revela que sus constructores prefirieron concentrarse más en el factor cualitativo que en el cuantitativo./ Fue en este período clásico/ cuando se construyeron centros religiosos con plataformas 
parecidas a las del Acrópolis/, y columnatas formadas por columnas cuadradas o redondas/, esculpidas en bajorrelieve./

Del último período maya se han preservado ruinas en mejor estado/, en la costa oriental de Yucatán y en las vecinas islas de las Mujeres y Cozumel./ Estas ruinas ayudaron a los primeros cronistas españoles a opinar sobre la manera en que vivían los mayas del Nuevo Imperio./ En el centro de las ciudades se encontraban los templos y las hermosas plazas; / a su alrededor se alzaban las mansiones de los nobles y sacerdotes, / y más allá, las casas del pueblo. /

Chichén Itzá, al noroeste de Yucatán/, fue la metrópoli más imponente del período posclásico./ Allá encontramos dos estilos distintos:/ uno típicamente maya /y otro con reminiscencias del estilo tolteca. / Debido a la influencia tolteca,/ pilares con forma de serpiente emplumada ornamentaban los templos./ Hasta ahora se han descubierto siete pirámides y un inmenso castillo./ Sus columnatas, usadas tal vez para los consejos de guerra y concilios religiosos, reúnen unas mil columnas alrededor de la inmensa plaza abierta/ que probablemente servía de mercado./

Los mayas no conocieron el $\underline{\text { arco, }}$ / aunque construyeron edificios circulares,/ especialmente durante el período de influencia tolteca./ Al final del Nuevo Imperio/ se desarrolló un estilo exageradamente elaborado y decorado, parecido al barroco. / Después ocurrió la repentina destrucción de la civilización maya,/ cuyas causas aún no se han podido determinar./ Entonces la exuberante vegetación comenzó a invadir y cubrir las gigantescas construcciones./ 


\section{APPENDIX B: DEMOGRAPHIC DATA QUESTIONNAIRE}

1. Name:

2. Major:

3. Age:

4. How many years have you studied Spanish?

5. Have you traveled to a Spanish-speaking country? If so, to which country did you travel, and how long was your stay?

Please answer the following questions on a scale of 1 to 5 , with 1 being no knowledge and 5 being expert knowledge.

6. Please rate your knowledge of Latin American music.

1

2

3

4

5

7. Please rate your knowledge of Latin American architecture.

$\begin{array}{lllll}1 & 2 & 3 & 4 & 5\end{array}$

8. Please rate your knowledge of Latin American art.

1

2

3

4

5 


\section{APPENDIX C: GEFT SAMPLE ITEM}

The following is a simple figure:

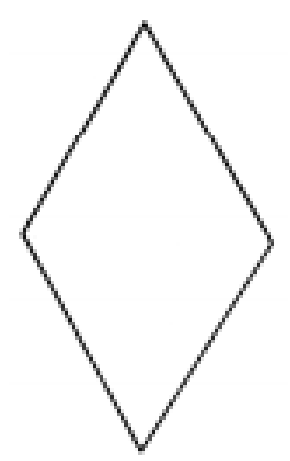

Participants are instructed to find the simple figure (such as the one shown above) hidden in the complex figure (such as the one shown below).

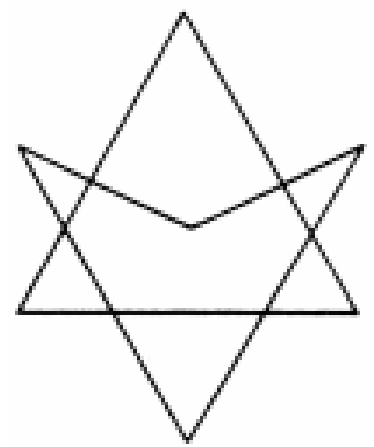




\section{APPENDIX D: READING PROGRAM}

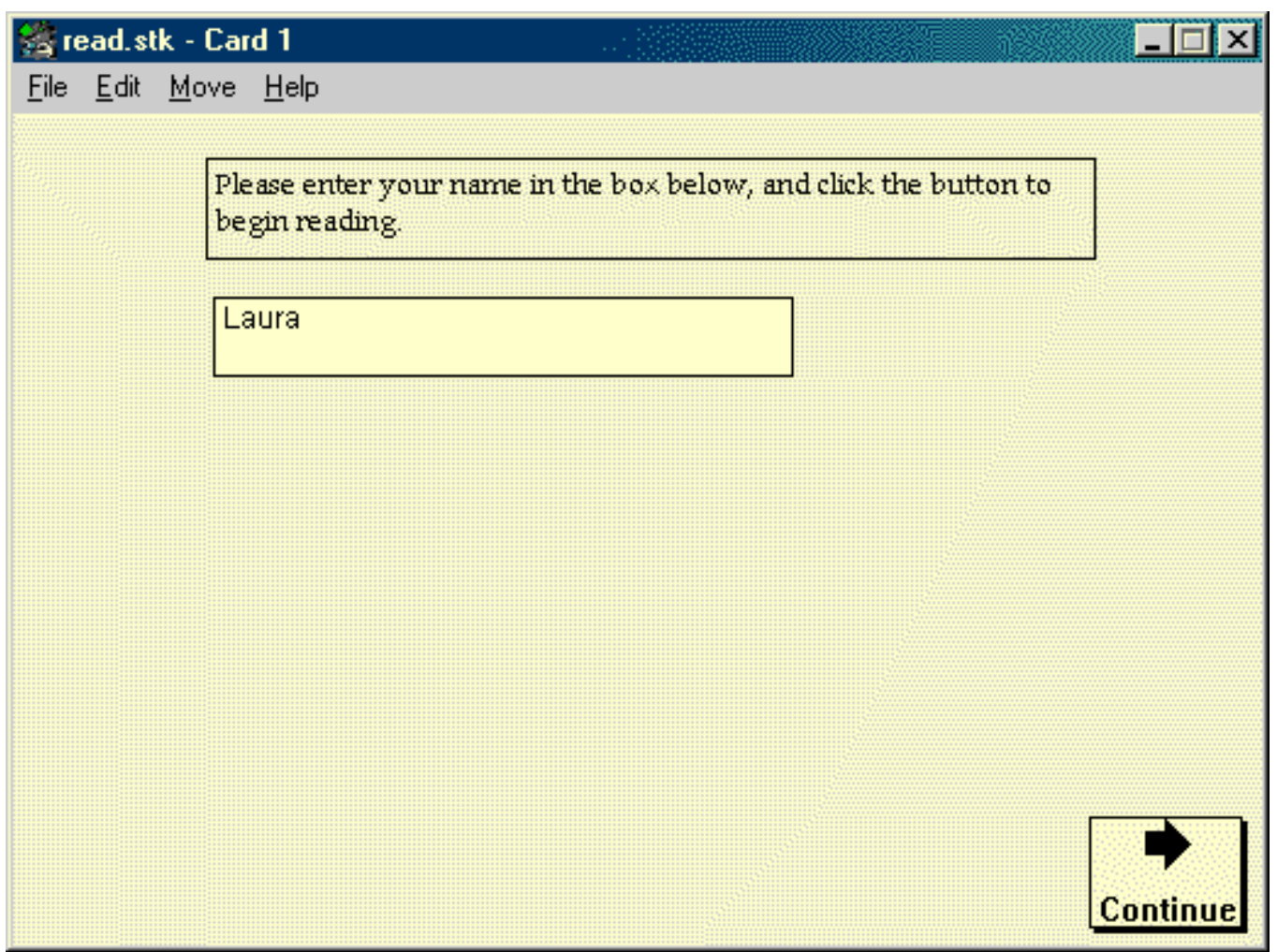




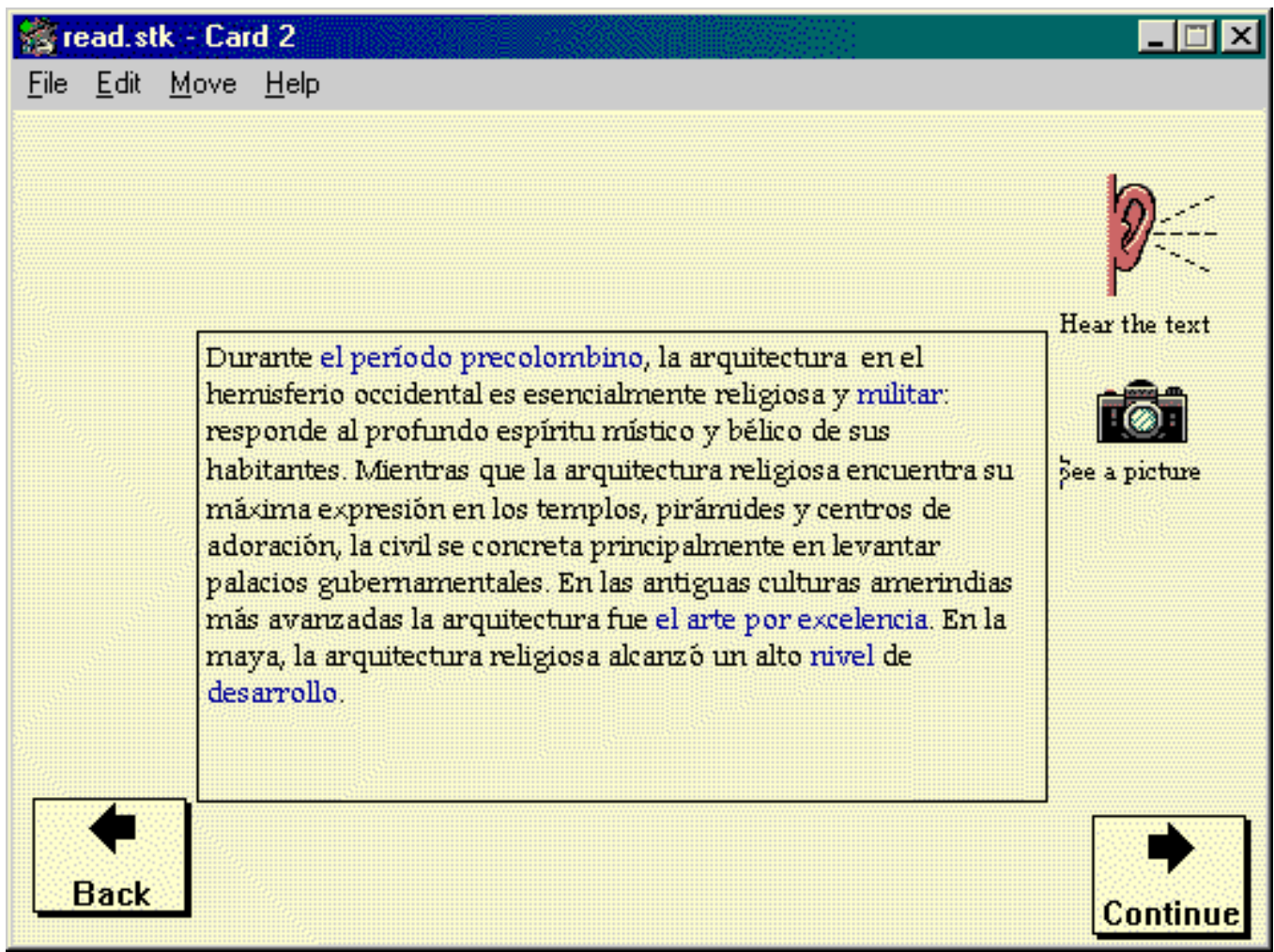




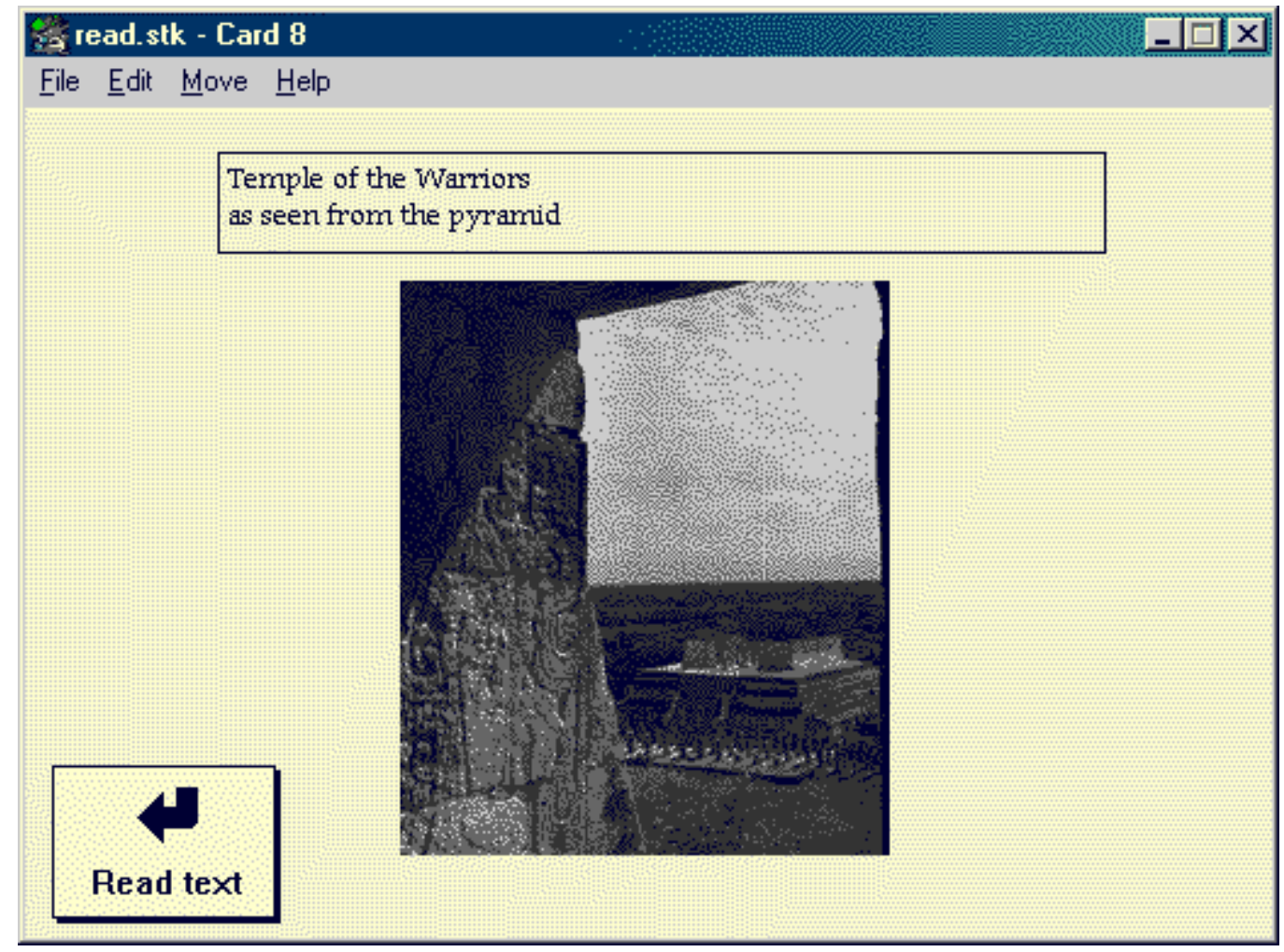




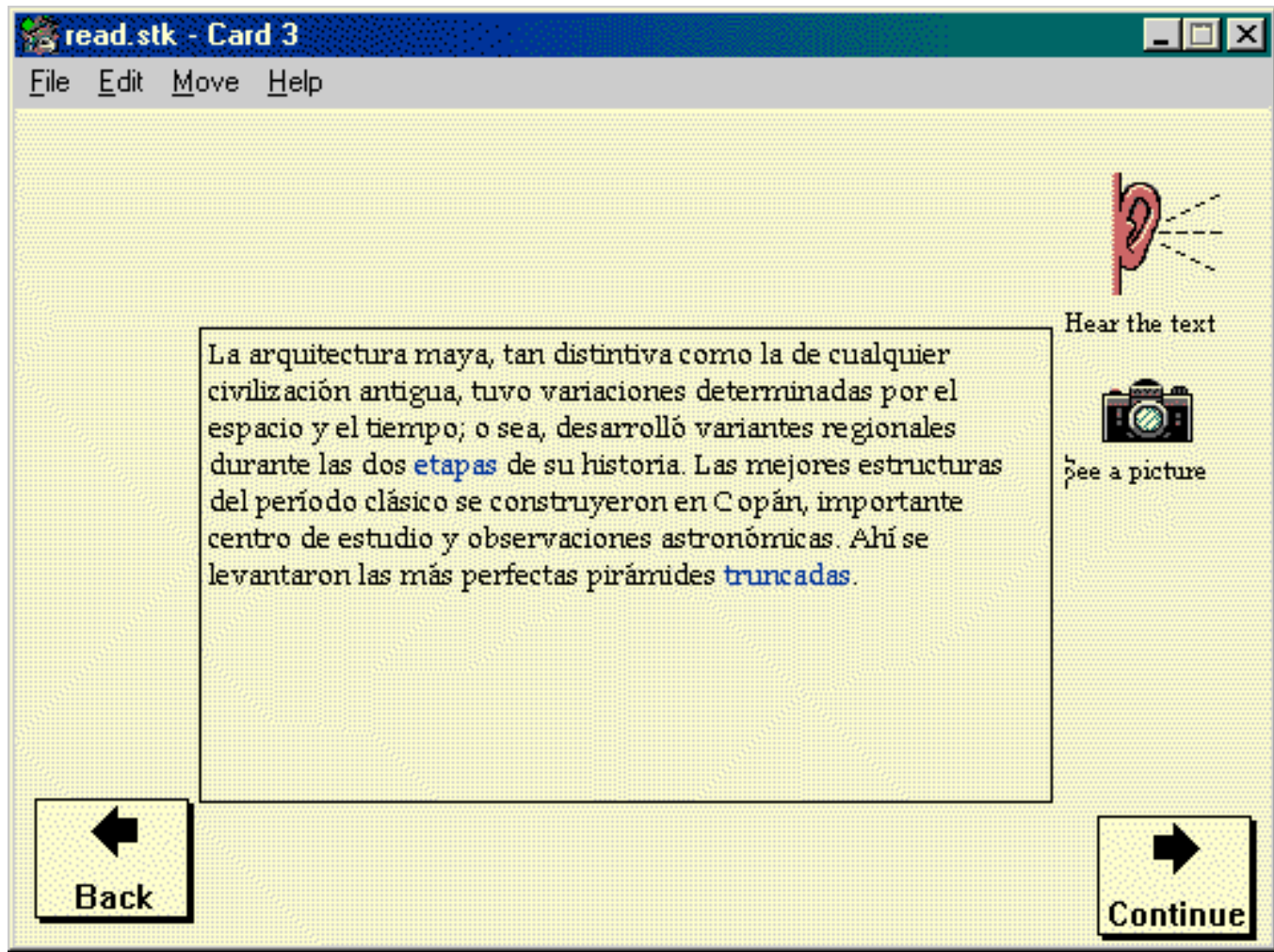




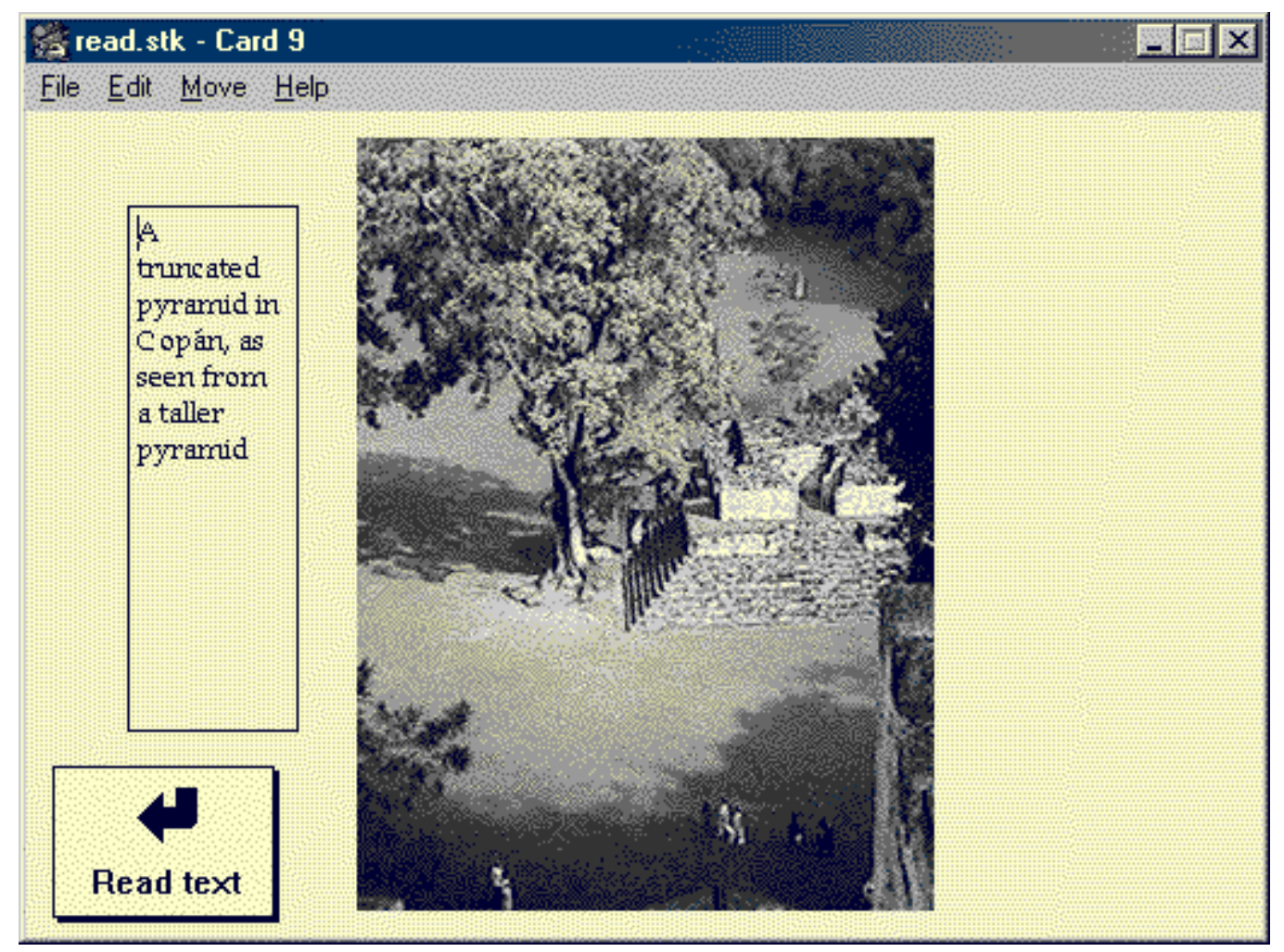




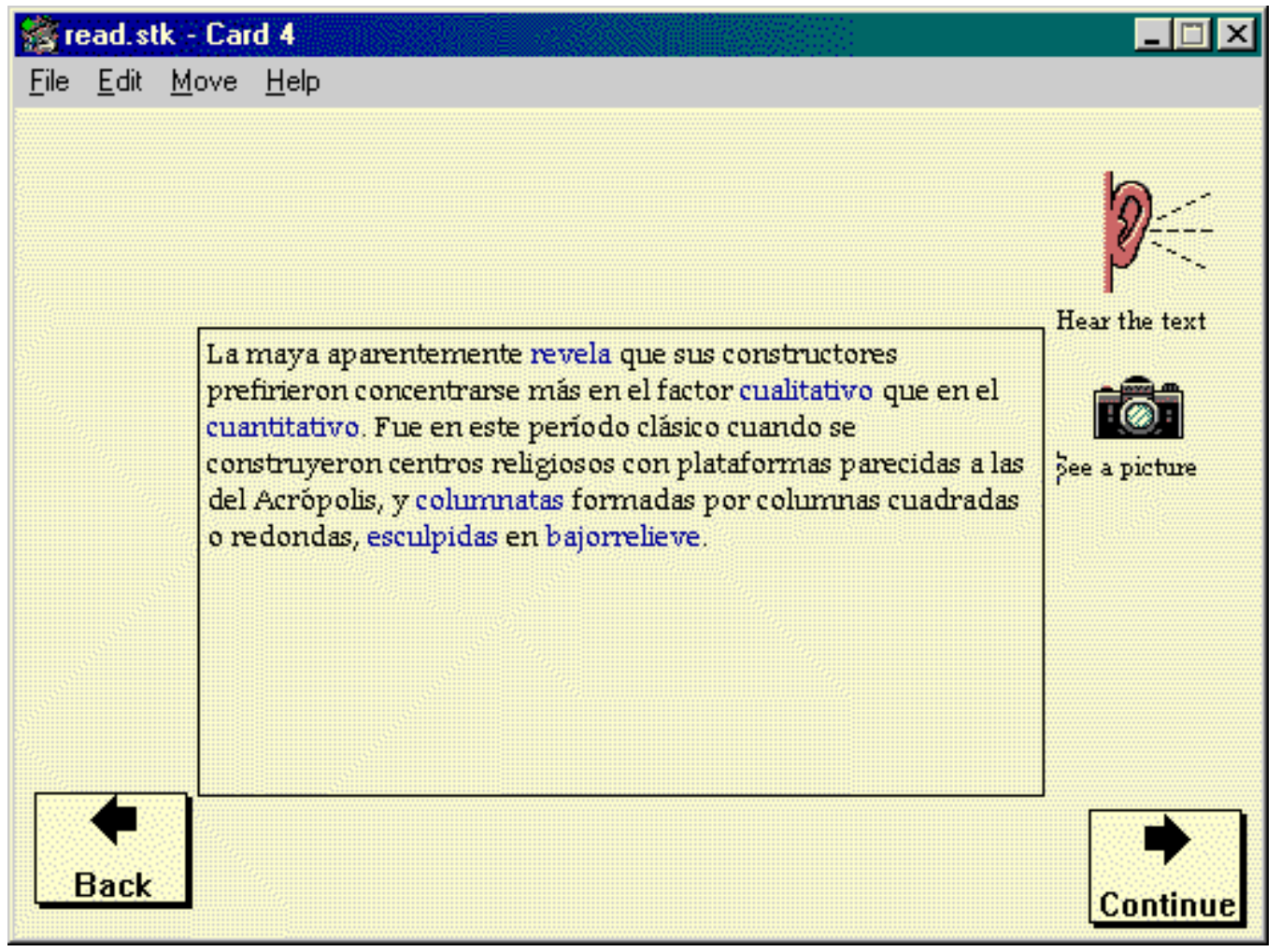




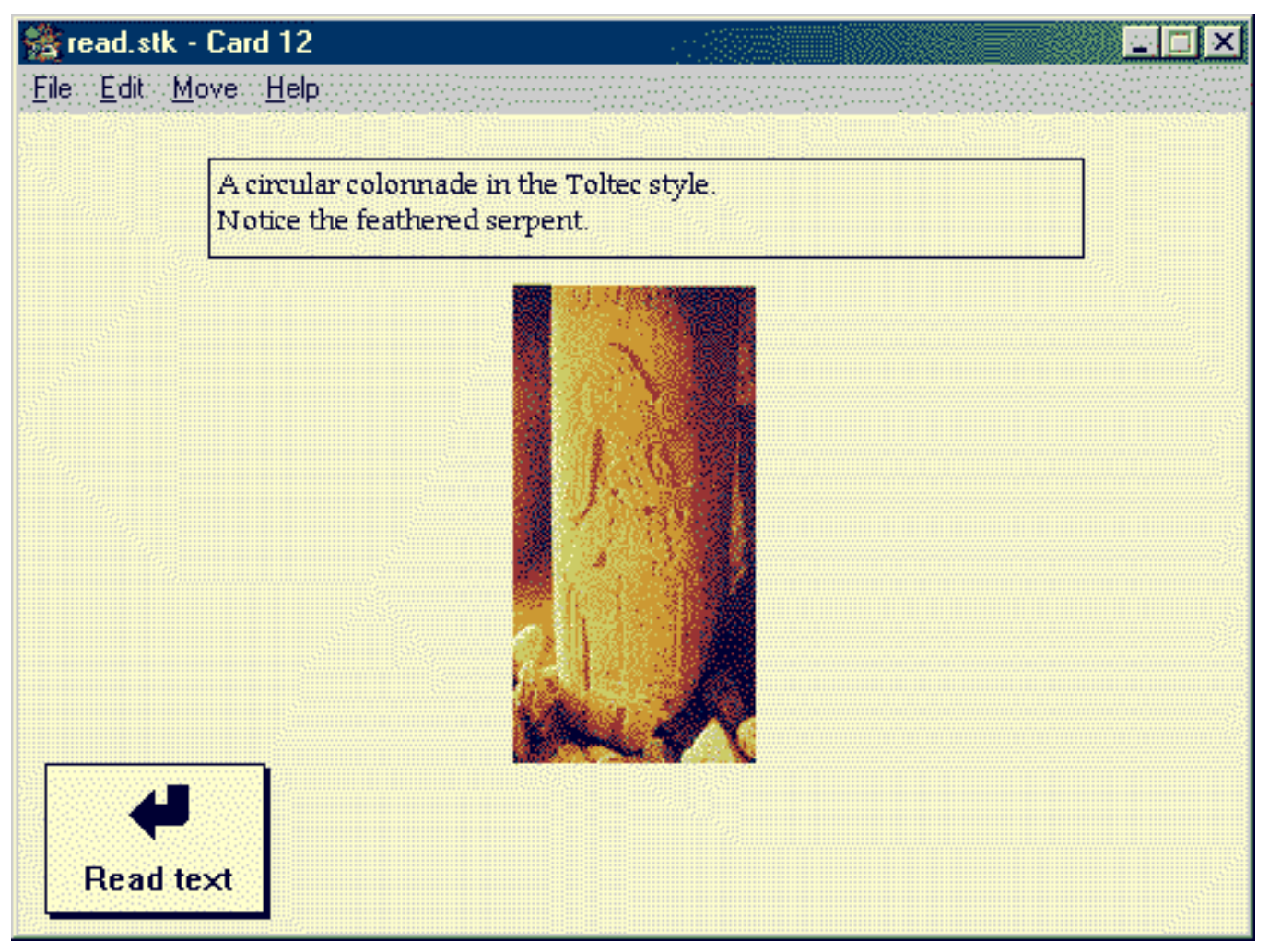




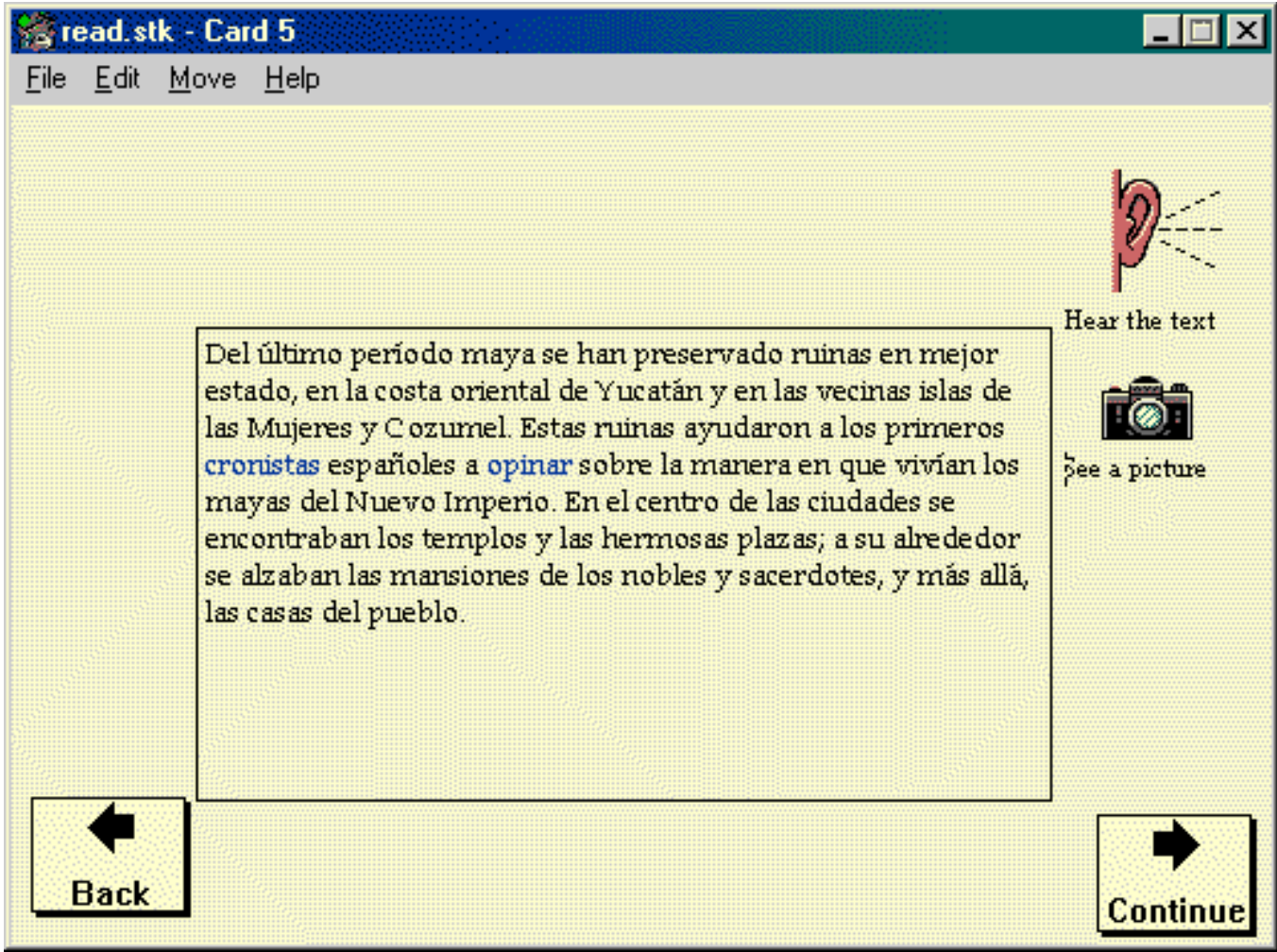




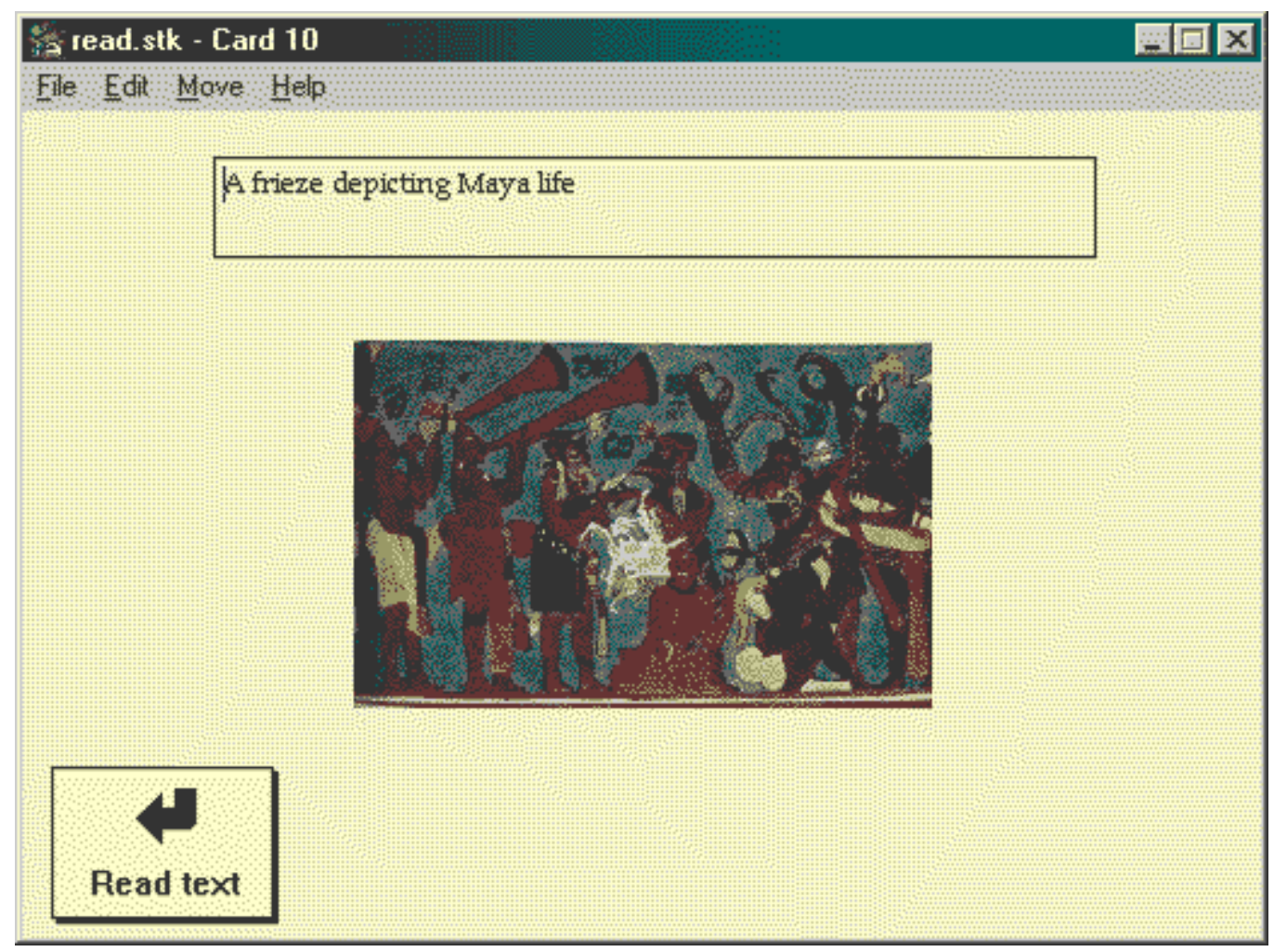




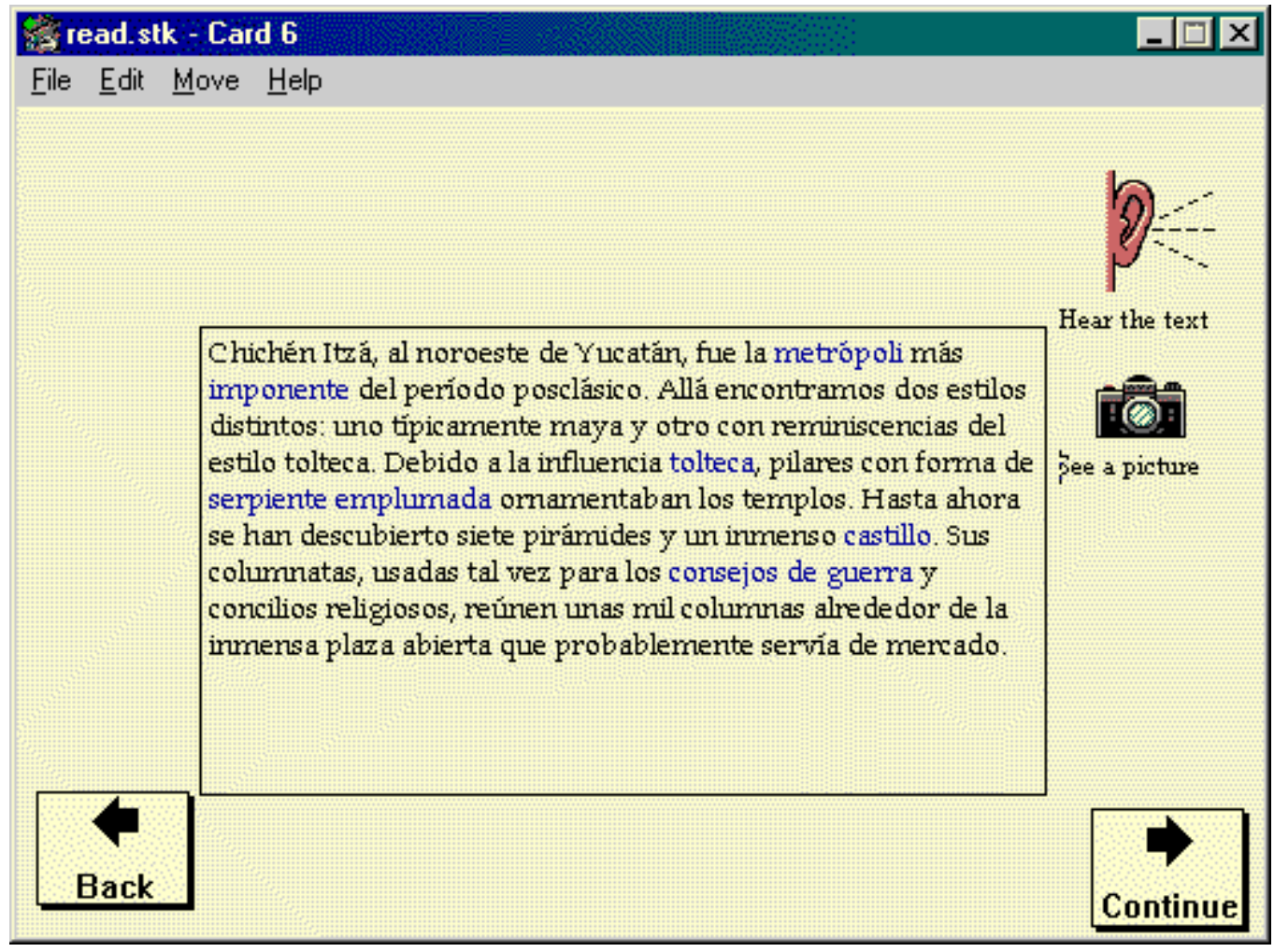




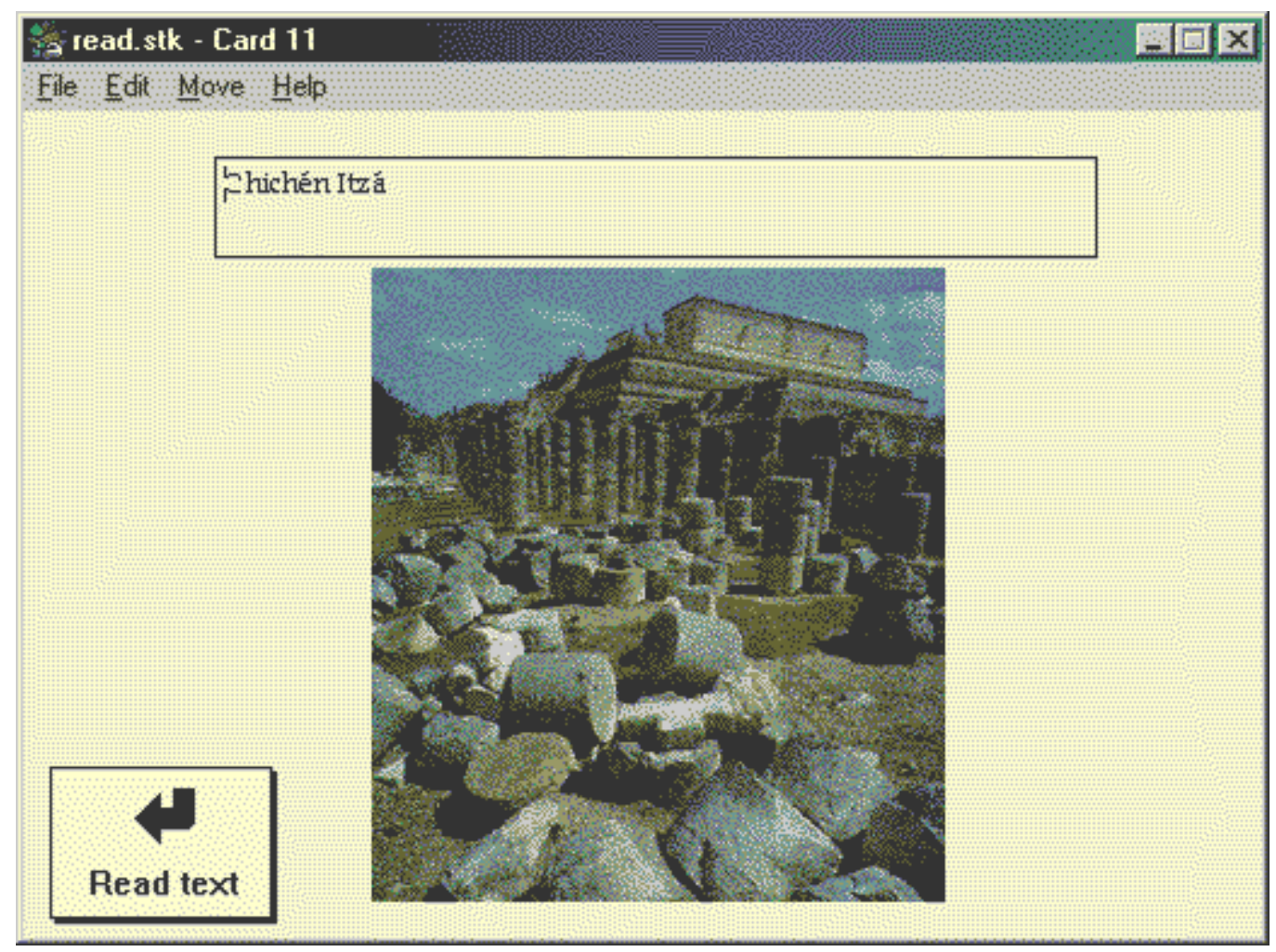




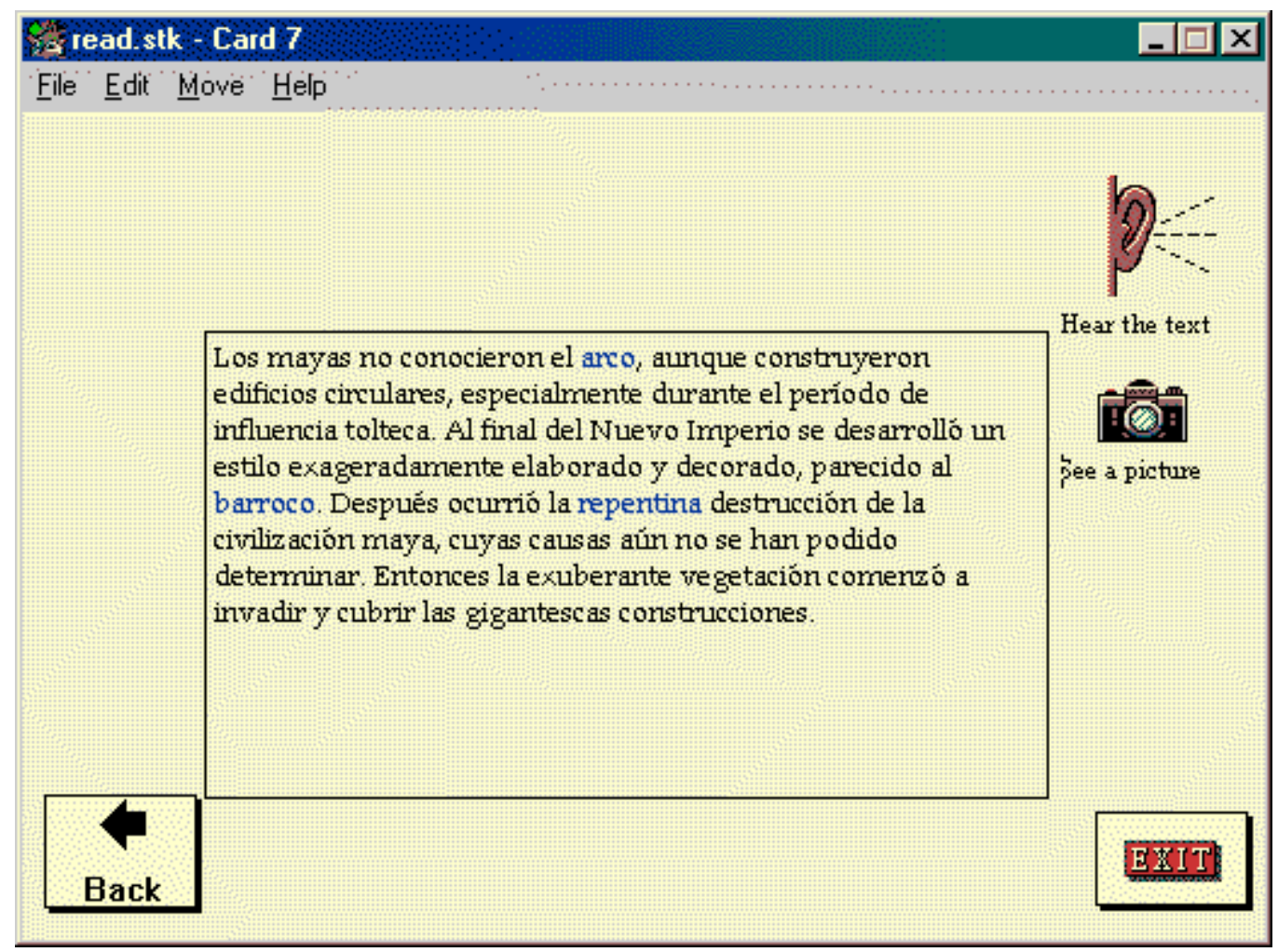




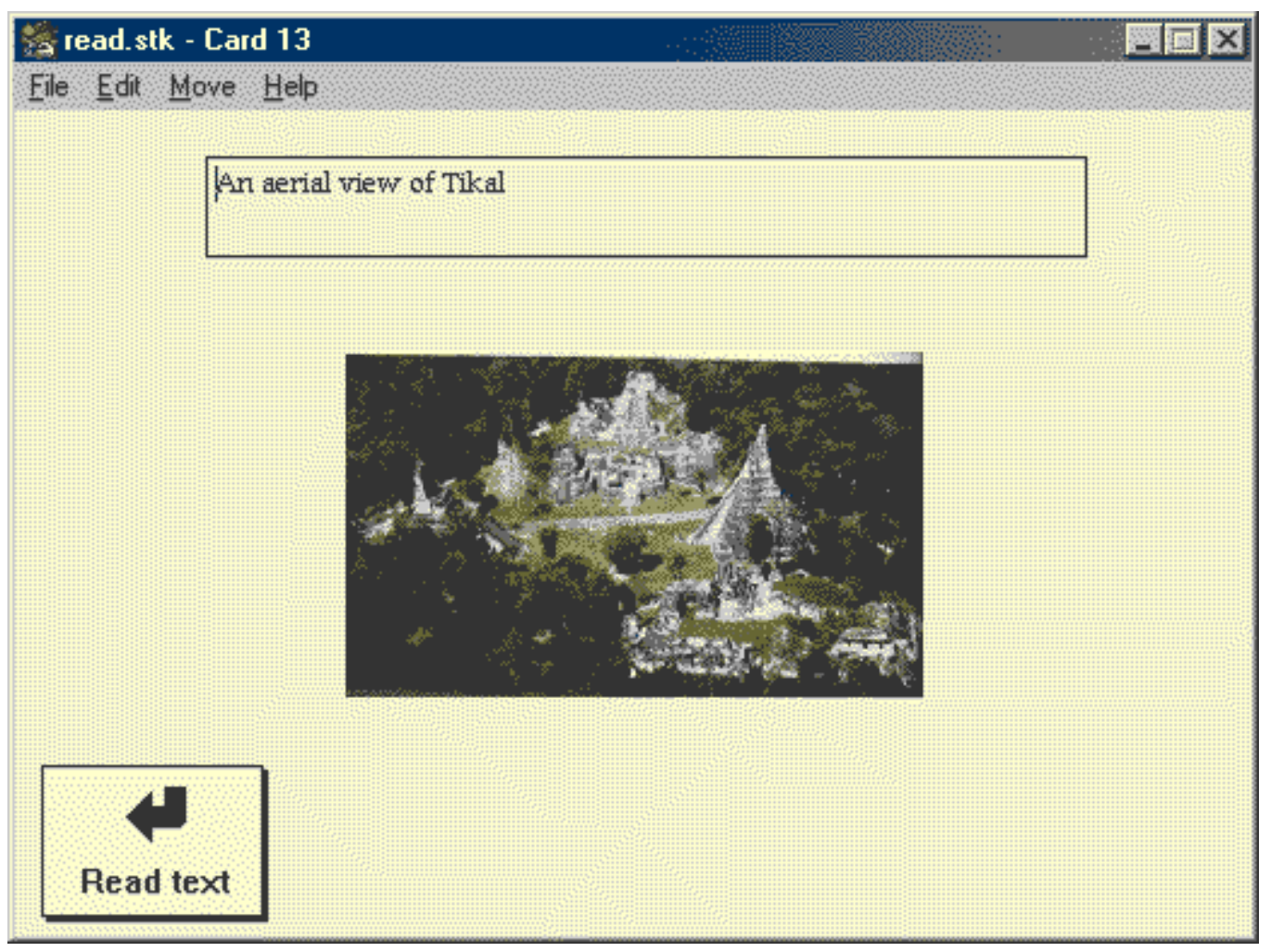




\section{REFERENCES}

Aspatore, J. V. (1984). "But I don't know all the words!" Foreign Language Annals, 14, (4), 297-299.

Aweiss, S. (1994-5). Situating learning in technology: The case of computer-mediated reading supports. Journal of Educational Technology Systems, $23(1), 63-74$.

Bensoussan, M. (1986). Beyond vocabulary: Pragmatic factors in reading comprehension--culture, convention, coherence, and cohesion. Foreign Language Annals, 19 (5), 399-406.

Brown, H. D. (1977). Cognitive and affective characteristics of good language learners. Paper presented at the meeting of the Los Angeles Second Language Research Forum, Los Angeles, CA.

Carroll, J. B. (1963). Research on teaching foreign language. In J. Gage (Ed.), Handbook of Teaching on Research. (pp. 1060-1100). Chicago: Rand McNally \& Co.

Carter, E. F. (1988). The relationship of field dependent/field independent cognitive style to Spanish language achievement and proficiency: A preliminary report. Modern Language Journal, 72 (1), 21-30.

Chapelle, C. \& Green, P. (1992) Field independence/dependence in second-language acquisition research. Language Learning, 49, (1), p. 47-83. 
Chapelle, C. \& Jamieson, J. (1986). Computer-assisted language learning as a predictor of success in acquiring English as a second language. TESOL Quarterly, 20 (1), 27-45.

Chapelle, C. \& Roberts, C. (1986). Ambiguity tolerance and field independence as predictors of proficiency in English as a second language. Language Learning, 36 (1), 27-45.

Chun, D. M. \& Plass, J. L. (1996a). Effects of multimedia annotations on vocabulary acquisition. Modern Language Journal, 80 (2), 183-198.

Chun, D. M. \& Plass, J. L. (1996b). Facilitating reading comprehension with multimedia. System, 24 (4), 503-519.

Crawford, A. N. (1984). A Spanish language Fry-type readability procedure: Elementary level. Bilingual Education Paper Series, 7 (8) (ERIC 273119).

Dalgish, G. M. (1987). Some uses of computers in teaching English as a second language: The issue of control. Computers in the Schools, 4 (1), 81-93.

Davis, J. N. (1989). Facilitating effects of marginal glosses on foreign language reading. Modern Language Journal, 71, (1), p. 41-48.

Davis, J. N. (1992). Reading literature in the foreign language: The comprehension/response connection. The French Review, 65 (3), 359-367.

Dunkel, P. (1990). Implications of the CAI effectiveness research for limited English proficient learners. Computers in the Schools, 7 (1-2), 31-52.

Fry, E. B. (1977). Fry's Readability Graph: Clarifications, validity, and extension to level 17. Journal of Reading, 21, p. 242-252. 
Fry, E. B. (1987). The varied uses of readability measurement today. Journal of Reading, 30, (4), P. 338-343.

Garrett, N. (1988) Computers in foreign language education: Teaching, learning, and language-acquisition research. ADFL Bulletin, 19 (3), 6-12.

Garrett, N. (1991). Language pedagogy and effective technology use. Applied Language Learning, 2 (2), 1-14.

Gilliam, B., Peña, S.C., \& Mountain, L. The Fry Graph applied to Spanish readability. The Reading Teacher, 33 (4), p. 426-430.

Goodenough, D.R., \& Karp, S.A. (1961). Field dependence and intellectual functioning. Journal of Abnormal and Social Psychology, 63, 241-246.

Grabe, W. (1991). Current developments in second language reading research. TESOL Quarterly, 25, (3), 375-406.

Gray, W.S., \& Leary, B. E. (1935). What Makes a Book Readable. University of Chicago Press: Chicago, IL.

Hannafin, M. J. \& Peck, K. L. (1988). The Design, Development and Evaluation of Instructional Software. New York: Macmillan.

Hansen, J. \& Stansfield, C. (1982). Student-teacher cognitive styles and foreign language achievement: A preliminary study. Modern Language Journal, 66, p. 263-273.

Hong, W. (1997). Multimedia computer-assisted reading in business Chinese. Foreign Language Annals, 3, p. 335-344. 
Hulstijn, J. (1993). When do foreign language readers look up the meanings of unfamiliar words? The influence of task and learner variables. The Modern Language Journal, 77 (2), 139-147.

Jamieson, J. (1994). A history of commitment in CALL. Paper presented at the Computers in Applied Linguistics Conference, Ames, IA.

Kang, S-H. \& Dennis, J. R. (1995). The effects of computer-enhanced vocabulary lessons on achievement of ESL grade schools children. Computers in the Schools, 11 (3), 25-35.

Lee, J. F. (1986a). Background knowledge and L2 reading. Modern Language Journal, 70 (4), 350-354.

Lee, J. F. (1986b). On the use of the recall task to measure L2 reading comprehension. Studies in Second Language Acquisition, 8, p. 201-212.

Leu, D. J. ,Jr. \& Kinzer, C. K. (1999). Effective literacy instruction (4th ed.). Upper Saddle River, NJ: Merrill.

Levine, M. G. \& Haus, G. J. (1985). The effects of background knowledge on the reading comprehension of second language learners. Foreign Language Annals, 18 , (5), 391-397.

Liou, H-C. (1997). The impact of WWW texts on EFL learning. Computer Assisted Language Learning, 10 (5), 455-478.

Liu, M. (1992). The effect of hypermedia assisted instruction on second language learning: A semantic-network-based approach. Unpublished doctoral dissertation, West Virginia University, Morgantown. 
Liu, M. (1995). Contextual enrichment through hypermedia technology: Implications for second-language learning. Computers in Human Behavior, 11 (3-4), 439-450.

Liu, M. \& Reed, W. M. (1995). The effect of hypermedia assisted instruction on second language learning. Journal of Educational Computing Research, 12 (2), 159-175.

Loew, H. Z. (1984). Developing strategic reading skills. Foreign Language Annals, 17 (4), 301-303.

Mayer, R. E. \& Sims, V. K. (1994). For whom is a picture worth a thousand words? Extensions of a dual-coding theory of multimedia learning. Journal of Educational Psychology, 86 (3), 389-401.

Mayer, R. E. (1997). Multimedia learning: Are we asking the right questions? Educational Psychologist, 32 (1), 1-19.

Melendez, E. J. \& Pritchard, R. H. (1985). Applying schema theory to foreign language reading. Foreign Language Annals, 18 (5), 399-403.

Morgan, L. Z. (1994). Reading strategies: Issues in the computerization of Machiavelli's "Il demonio che prese moglie." Italica, 71 (4), 505-520.

Omaggio, A. C. (1979). Pictures and second language comprehension: Do they help? Foreign Language Annals, 12, 107-116.

Plass, J. L., Chun, D. M., Mayer, R. E., \& Leutner, D. (1998). Supporting visual and verbal learning in a second-language multimedia learning environment. Journal of Educational Psychology, 90 (1), 25-36. 
Reinking, D., \& Schreiner, R. (1985). The effects of computer-mediated text on measures of reading comprehension and reading behavior. Reading Research Quarterly, 20 (5), 536-552.

Reynolds, R. E., Taylor, M. A. , Steffensen, M. S., Shirley, L. L., \& Anderson, R. C. (1982). Cultural schemata and reading comprehension. Reading Research Quarterly, 17 (3), 353-366.

Schwartz, M. (1995). Computers and the language laboratory: Learning from history. Foreign Language Annals, 28 (4), 527-535.

Steffensen, M. S., Joag-Dev, C., \& Anderson, R. C. (1979). A cross-cultural perspective on reading comprehension. Reading Research Quarterly, 15 (1), p. 1029.

Spaulding, S. A Spanish Readability Formula. The Modern Language Journal, 40 (8), p. 433-441.

Vari-Cartier, P. (1981). Development and validation of a new instrument to assess the readability of Spanish prose. Modern Language Journal, 65, (2), p. 141148.

Warschauer, M. (1996). Computer-assisted language learning: An introduction. In S. Fotos (Ed.), Multimedia Language Teaching (pp. 3-20). Tokyo: Logos International.

Witkin, H. A., Moore, C. A., Goodenough, D. R., \& Cox, P. W. (1977). Field-dependent and field-independent cognitive styles and their educational implications. Review of Educational Research, 47, (1), p. 1-64. 
Witkin, H. A., Oltman, P. K., Raskin, E., \& Karp, S. A. (1971). A manual for the Embedded Figures Test. Palo Alto, CA: Consulting Psychologists Press.

Woloshyn, V. E., Paivio, A., \& Pressley, M. (1994). Use of elaborative interrogation to help students acquire information consistent with prior knowledge and information inconsistent with prior knowledge. Journal of Educational Psychology, 86 (1), 79-89. 